\title{
SISTEMÁTICA DE GESTÃO EFICAZ \& SUSTENTÁVEL REDE DE CÉLULAS INTEGRADAS DE CONTROLE
}

Rafael Rogério Brunelli ${ }^{1}$

\begin{abstract}
RESUMO
O sucesso das organizações depende basicamente da motivação e do comprometimento que todos os colaboradores possuem. É fundamental que se possa entender algumas das dificuldades que reduzem o grau de comprometimento, a satisfação, a eficiência nas operações realizadas, buscando-se assim informações específicas e estudos aplicados, desenvolvendo desta forma, resultados baseados em novas práticas de gestão. 0 artigo em questão apresenta novas soluções para a gestão de atividades operacionais em Unidades de Educação e Tecnologia SENAI - FIERGS, visando basicamente a implementação de sistemáticas de gestão baseadas em células integradas de controle. Cada célula representa uma determinada área de atividades locais, integradas e controladas de forma racional e eficaz. Apresenta-se neste artigo também, resultados de uma pesquisa de satisfação e cooperação técnica, relacionada à nova sistemática de gestão, parâmetros que indicam novos entendimentos, ações e resultados. No desenvolvimento deste artigo, que se trata de um estudo de caso, se oferece de forma racional, uma série de oportunidades e sugestões de melhorias para muitas das áreas de maior impacto nas operações e resultados educacionais, técnicos e tecnológicos das Unidades SENAI - FIERGS.
\end{abstract}

Palavras-chave: Gestão. Células Integradas de Controle. Sustentabilidade

\footnotetext{
${ }^{1}$ Mestre, e-mail: rafael.brunelli@senairs.org.br
} 


\section{INTRODUÇÃO}

O significado da palavra "gestão" possui uma amplitude que pode vir a deixar dúvidas sobre alguns pontos e processos, que normalmente pratica-se em diversas instituições.

A "gestão", do latim "gestio", refere-se à ação e ao efeito de gerir ou de administrar, conforme define a filosofia científica. Gerir consiste em realizar múltiplas ações que conduzem à realização de um negócio ou de desejo individual ou coletivo. Administrar, por outro lado, consiste em governar, dirigir, ordenar ou organizar.

A gestão, conforme afirma Pua e Debbie (2012), Aaker (2007) e Camiloti (2010), envolve todo um conjunto de trâmites que são levados de forma muito objetiva, com o intuito de resolver de forma rápida um assunto ou concretizar um projeto, gerando receitas e bem estar dos envolvidos, aumentando o comprometimento das partes.

Gestão estratégica, segundo Ginter e White (1982) e Faria (2009), tem evoluído durante o tempo e continuará a evoluir. Como resultado, é perceptível a falta de consenso sobre o que precisamente o termo significa. Apesar deste impasse, conforme apresenta Ansoff (1984), Bower (1986) e Glavam (2010), a gestão estratégica é executada em muitas organizações atualmente e muitas delas se beneficiam significativamente deste processo, aumentando seu desempenho.

A gestão eficaz, estratégica e sustentável, evidenciada nas obras científicas de Certo e Peter (1993), Drucker (1994) e Chiavenato (2009a), é um processo contínuo e iterativo, que visa manter uma organização como um conjunto apropriadamente integrado ao seu ambiente racional, produtivo e sustentável. Esta integração, conforme comenta Fávaro (2011) em sua obra, aumenta muito o comprometimento e satisfação dos envolvidos nas atividades realizadas nos ambientes de trabalho.

Embora a definição de gestão estratégica, eficaz e sustentável, pareça clara e simples, realmente implementar o processo em uma determinada organização, tanto com foco geral (organização como um todo) como específico (unidades operacionais - locais), é normalmente muito complicado, explicam os especialistas Certo e Peter (1993), Rock e Eisthen (1983), Ramos (1983) e Farias (2003).

Com base em obras, dentre os quais Certo e Peter (1993), Ginter e White (1982) e Campos (1994), algumas das responsabilidades da gestão, acima descrita, que contribuem para essas dificuldades de implantação, são conhecidas como "definição da missão", "filosofia da instituição", "políticas da organização", "objetivos diretos do negócio", "estratégias e ações", "planejamento e estrutura da empresa", "pessoal adequado e especializado", "estabelecimento de procedimentos de operação", "instalações", "capital", "padrões de operação", "informações de acesso, de controle e de operação", "mantenência de pessoal sempre ativo - motivação constante". 
Uma sistemática de gestão inovativa, eficaz, estratégica e sustentável, conforme relatos das obras de Deschamps (2011) e no Um Guia... (2004), deve enfatizar a passagem por uma série de etapas de planejamento e de implantação de estratégias específicas, um projeto específico para cada área envolvida, sempre levando em consideração um grande aspecto que são as pessoas, os profissionais envolvidos, definidos por seus gostos e suas aptidões profissionais.

As principais etapas deste processo, segundo Certo e Peter (1993) e Kardec, Flores e Seixas (2002), englobam itens importantes e vitais, como "desenvolvimento da análise do ambiente interno e externo da organização, tais como fatores econômicos, tecnológicos, políticos e sociais, bem como recursos humanos e materiais, relações e valores pessoais", "estabelecimento da diretriz organizacional, com a elaboração da missão e dos objetivos de curto, médio e longo prazo", "formulação de estratégias organizacionais, delineando cursos apropriados de ação, a fim de se atingir com sucesso os reais objetivos definidos", "implementação da estratégia definida para determinada área de ação, pois o sucesso dos resultados de muitas organizações está diretamente envolvido com a capacidade/ sucesso na implementação destas estratégias", "controle de ações estratégicas, que podem ser desenvolvidos com base em muitas formatações específicas, mas que devem produzir resultados de real controle das ações implementadas nas sistemáticas de gestão".

Além de se beneficiar de várias formas, dentre elas financeiramente, as instituições podem gozar de diversas outras vantagens na implementação de "sistemas de gestão eficaz, estratégica e sustentável". Este tipo de gestão, de formatação de processos específicos e entendíveis, pode levar os membros da organização a se comprometerem com a realização, não somente de metas a curto e médio prazo, mas de metas a longo prazo. Esse aumento no compromisso, normalmente surge quando os membros participam ativamente das várias metas organizacionais, bem como das estratégias para se atingir essas metas.

A proposta aqui apresentada, com base em uma sistemática de gestão eficaz e sustentável, com definições em "células integradas de controle", visa obter o máximo de comprometimento, responsabilidade, controle e desempenho financeiro e de qualidade de vida para os profissionais e para a organização Serviço Nacional de Aprendizagem Industrial (SENAI) e Federação das Indústrias do Rio Grande do Sul (FIERGS).

Em virtude de diversas "falhas" detectadas durante o processo de gestão nas Unidades Operacionais SENAI - FIERGS, realizado inicialmente no período de 2011, nas Unidades CEP SENAI de Passo Fundo, AEP SENAI de Carazinho e na AEP SENAI de Marau, e posteriormente também verificado, após o ano de 2012, nas Unidades CEP SENAI Giuseppe Fasolo de Bento Gonçalves, AEP SENAI de Veranópolis e AEP SENAI de Nova Prata, verificou-se a necessidade da implantação de uma nova metodologia local de gestão eficaz, estratégica e sustentável, que envolvesse módulos de controle integrados (células de controle). 
Esta sistemática prevê definições de responsabilidades locais, incremento do conhecimento corporativo por parte de todos os integrantes e aumento, fortemente perceptível, nos resultados das diversas ações realizadas pelas referidas Unidades Operacionais SENAI - FIERGS.

Acredita-se que colaboradores bem preparados e informados de suas atribuições e responsabilidades, engajados, envolvidos e devidamente comprometidos com as metas de uma organização, podem trazer diversos benefícios em curto prazo.

Quando se sabe como fazer e o que fazer, de forma devidamente motivada, alcança-se resultados de destaque, otimizados e eficazes.

Para compreender, avaliar e destacar idéias como parte deste estudo, aplicou-se uma pesquisa de campo, para avaliar a satisfação, aplicabilidade e resultados específicos ligados à "Sistemática de Gestão Eficaz e Sustentável", aos colaboradores envolvidos com estes processos específicos nas Unidades Operacionais SENAI - FIERGS de Bento Gonçalves, Veranópolis e Nova Prata. É importante ressaltar que pesquisa de campo, conforme afirma Gil (2002), basicamente é uma pesquisa de levantamento de dados. Informações adicionais sobre os principais conceitos e tipos de coletas de dados, bem como os procedimentos adotados para a realização dos levantamentos de campo, estão apresentados detalhadamente no item 3, especificadamente nos subitens 3.1 e 3.2 deste artigo.

Todos os resultados obtidos nestes levantamentos de dados, bem como as conclusões destacadas, em sua totalidade são analisados no presente artigo.

\subsection{Objetivo Geral}

a) apresentar de forma detalhada a nova sistemática de "Gestão Eficaz e Sustentável", baseada em "Células Integradas de Controle" (Fluxos de Gestão, Responsabilidades e Controle), apoiada em processos de Gestão Corporativa do SENAI e desenvolvidas para serem aplicadas em Unidades Operacionais da rede SENAI do Rio Grande do Sul - FIERGS; apontando os níveis, com base nos colaboradores das referidas UOs, de satisfação, comprometimento, eficácia e resultados em curto prazo, na implantação e operacionalização da "Sistemática de Gestão Eficaz e Sustentável - Células Integradas de Controle" nas Unidades Operacionais SENAI - FIERGS (CEP SENAI Giuseppe Fasolo de Bento Gonçalves, AEP SENAI de Veranópolis e AEP SENAI de Nova Prata). 


\title{
1.2 Objetivos Específicos
}

a) aplicar pesquisa de campo, para colaboradores de áreas específicas, relacionada à "Sistemática de Gestão Eficaz e Sustentável - Células Integradas de Controle";

b) analisar os referidos níveis de satisfação, comprometimento, eficácia e resultados, na implantação e operacionalização da "Sistemática de Gestão Eficaz e Sustentável - Células Integradas de Controle;

c) apontar possíveis "Oportunidades de Melhoria", com base nos dados e apontamentos levantados em pesquisa de campo e nos resultados gerais obtidos pelas Unidades Operacionais SENAI - FIERGS.

\section{SISTEMÁTICA DE GESTÃO EFICAZ E SUSTENTÁVEL}

Rumo a "Excelência Organizacional", pensar e agir estrategicamente, utilizando-se padrões de trabalho, tende a ser um movimento mundial.

Kardec, Flores e Seixas (2002, p. 3) conceitua este novo movimento como:

\begin{abstract}
Esta nova postura é fruto dos novos desafios que se apresentam neste novo cenário de uma economia de alto desempenho, de fronteiras globais e altamente competitiva, onde as mudanças se sucedem em alta velocidade e a gestão eficaz de processos se torna uma das atividades fundamentais de um processo produtivo ágil e moderno. Nestes cenários não existem mais espaços para improvisos: competência, criatividade, flexibilidade, velocidade, cultura de mudança e trabalho em equipes são características básicas de organizações que possuem a competitividade como razão de ser de sua sobrevivência. Para as pessoas estas características são essenciais para garantir a empregabilidade de cada um!
\end{abstract}

A condução moderna dos negócios requer uma mudança, muitas vezes, profunda de mentalidade e de posturas, afirmam Kardec, Flores e Seixas (2002) e Campos (1994).

A credibilidade adquirida pelo SENAI em 70 anos de trabalhos voltados as áreas de Educação e Tecnologia, proporcionam um vasto campo de aprendizados coletivos e individuais em novos padrões de Gestão de Alto Desempenho, utilizando-se Sistemáticas e Padrões para referenciar estas práticas modernas e de resultados eficazes.

A “Nova Gestão Moderna”, na visão de Kardec, Flores e Seixas (2002, p. 3) é conceituada como:

A "nova gestão" deve estar sustentada por uma visão de futuro e regida por processos de gestão onde a satisfação plena de seus clientes seja resultante da qualidade intrínseca dos seus produtos e serviços e a qualidade total dos seus 
processos seja o balizador fundamental. Ao invés de se falar em "mudança de cultura", que é um processo lento não condizente com as necessidades atuais, é preciso que a nova gestão implemente uma "cultura de mudanças", onde o inconformismo com a perpetuação de paradigmas e de práticas seja constante.

\subsection{A Organização SENAI e os Processos de Gestão Aplicados}

O Serviço Nacional de Aprendizagem Industrial (SENAI) é uma entidade que tem como objetivo promover o desenvolvimento e o aprimoramento da indústria nacional. Atua na capacitação de profissionais e no aperfeiçoamento dos produtos e processos das indústrias, por meio de cursos e serviços técnicos e tecnológicos. Administrado nacionalmente pela Confederação Nacional da Indústria (CNI) e pelas Federações das Indústrias nos Estados, o SENAl é normatizado por um conselho nacional e por conselhos regionais, que definem a política de atuação da entidade.

Graças à flexibilidade de sua estrutura e de seus processos, o SENAI é o maior complexo de educação profissional da América Latina. Diretamente ligados a um Departamento Nacional, 27 Departamentos Regionais levam seus programas, projetos e atividades a todo o território nacional, oferecendo atendimento adequado às diferentes necessidades locais e contribuindo para o fortalecimento da indústria e o desenvolvimento pleno e sustentável do País. O Departamento Regional do Rio Grande do Sul, vinculado ao Sistema FIERGS, participa do desenvolvimento da comunidade industrial do Estado, atuando na capacitação de pessoas com ensino de qualidade e proporcionando apoio técnico e tecnológico em diversas áreas. A Sede do Departamento Regional do SENAI-RS constitui o órgão central de administração do Sistema. Tem por finalidade estabelecer as diretrizes da organização, bem como desdobrar para suas Unidades Operacionais os objetivos emanados do Departamento Nacional do SENAI e da FIERGS.

As transformações socioeconômicas ocorridas no final do século XX trouxeram mudanças profundas ao mundo do trabalho. Tais desafios relacionam-se aos avanços tecnológicos e às novas expectativas das empresas, que enfrentam mercados globalizados extremamente competitivos. A busca por maiores níveis de produtividade e competitividade em âmbito mundial por parte do setor produtivo demanda das entidades de educação profissional novas estratégias de atuação. A educação profissional deve promover capacitação para atividades tecnicamente mais complexas, de maneira a proporcionar ao educando a capacidade de "aprender a aprender", avaliar, criticar, propor e tomar decisões.

Em Busca da "Excelência em Qualidade e Processos", o Departamento Regional do SENAI-RS tinha como objetivo, em 1992, implantar os programas de qualidade nas unidades operacionais, tendo como princípio sistematizar e direcionar as ações do SENAI-RS, visando contribuir efetivamente para a difusão da prática na Instituição e, junto ao empresariado do Rio Grande do Sul, os conceitos e a filosofia da qualidade. Em 
1994, implantou-se o Escritório da Qualidade (EQS) SENAI no Departamento Regional do SENAI-RS. No mês de setembro de 2003, iniciou-se o trabalho de Padronização, através do "Manual de Procedimentos para Rotinas Padronizadas", criado pelo Departamento Regional. O SENAI-RS tem estabelecido, documentado e implementado o Sistema de Gestão da Qualidade baseado nos requisitos da NBR ISO 9001 com o objetivo da melhoria contínua dos processos, assegurando a qualidade do produto/serviço final. Para conhecimento aprofundado, o Sistema de Gestão da Qualidade tem como diretrizes: "Identificar e executar os processos no SENAI-RS"; "Estabelecer a seqüência e interação dos processos"; "Definir as responsabilidades, critérios e métodos necessários para assegurar que a operação e o controle desses processos sejam eficazes"; "Assegurar e disponibilizar recursos e informações necessárias para apoiar a operação e o monitoramento dos principais processos"; "Medir, monitorar e analisar os principais processos"; "Implementar as ações necessárias para atingir os resultados planejados e a melhoria contínua".

Os valores e diretrizes organizacionais como Missão, Visão, Princípios e Valores são revisados no processo de revisão do Planejamento Estratégico e a Política da Qualidade na reunião de Análise Crítica pela Direção do Departamento Regional do SENAI-RS (Mapa estratégico FIERGS - SENAI - ASPLAN 2013 - 2017) (Figura 1). Esta prática tem como pró-atividade buscar assegurar que os valores e diretrizes organizacionais do SENAI-RS estejam atualizados e que sejam de conhecimento de todas as partes interessadas como clientes, força de trabalho e sociedade. A revisão do Planejamento é feita anualmente, nas reuniões de análise crítica corporativas, realizadas pelo Departamento Regional com participação da Direção Regional, Gerências e Diretores de Unidades, já a Missão, visão e princípios, valores a cada 2 anos, esta prática é de responsabilidade das Gerências de Planejamento e da Qualidade.

O SENAI, para operações/definições de organização, estruturas e processos, possui um "Manual da Qualidade", que apresenta a Missão, Política da Qualidade, Visão, Princípios e Valores, a forma de organização, implementação e manutenção do Sistema de Gestão da Qualidade do Departamento Regional e Unidades Operacionais. Este manual está estruturado de acordo com os requisitos da NBR ISO 9001.

A liderança da organização é exercida com base nas diretrizes corporativas estabelecidas no Planejamento Estratégico do SENAI-RS, mantendo sempre o foco na visão, missão, valores, política da qualidade e objetivos organizacionais. A alta Direção da Unidade Operacional exerce a liderança através da definição de metas para o Plano de Ação da Unidade Operacional e seu atendimento junto com as equipes de trabalho. A Direção local interage com as partes interessadas através das reuniões dos Conselhos Consultivos, transformando as demandas recebidas em projetos para a Unidade. A alta direção do DR-SENAI exerce a liderança na formulação das estratégias, através da revisão do Planejamento Estratégico, Balanced Scorecard (BSC) e Planos de Ação para as Gerências e Unidades Operacionais. Também exerce a liderança e interage com as partes interessadas, através de reuniões do Conselho Regional, onde são tratadas as demandas da comunidade empresarial e sociedade, bem como através das Reuniões 
de Gerentes, onde são tomadas e comunicadas as decisões para atendimentos das partes interessadas. Assim o envolvimento com as partes interessadas (clientes, força de trabalho, fornecedores, sociedade, entre outros), faz com que o interesse destas seja considerado na formulação das estratégias. Para manter esta sistemática tem-se a seguinte periodicidade das ações: "Planejamento Estratégico", a cada quatro anos; "Plano de Ação", anual; "BSC", anual; "Reuniões do Conselho Regional”, mensal; "Reuniões do Conselho Consultivo das Unidades Operacionais", três vezes ao ano.

Figura 1: Mapa Estratégico FIERGS - SENAI - ASPLAN 2013 - 2017

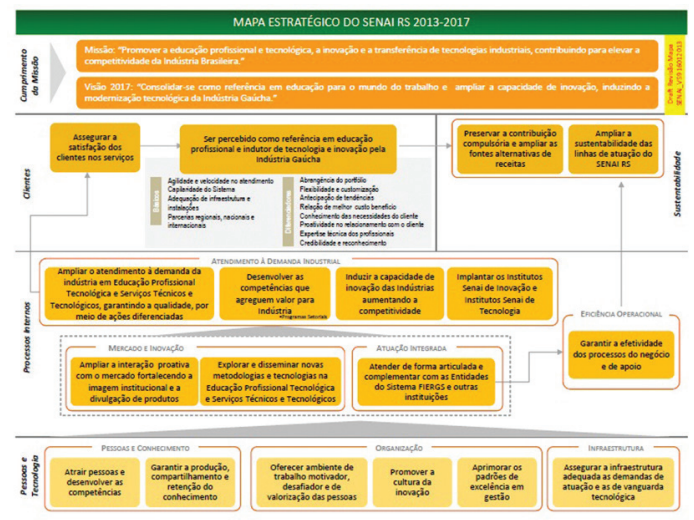

Fonte: Federação das Indústrias do Rio Grande do Sul (2013)

O exercício da liderança está coerente com todos os objetivos do Planejamento Estratégico, estão inter-relacionadas com o Plano de Ação da Unidade, sendo que há cooperação da direção com as partes interessadas. A Direção das UOs SENAI reporta-se diretamente à Direção de Educação e Tecnologia do SENAI-RS, que estabelece as principais diretrizes a serem cumpridas em consonância com o Departamento Nacional do SENAI e com os Conceitos Norteadores da Gestão. Os princípios e valores organizacionais são comunicados aos colaboradores através da distribuição dos documentos "Plano Estratégico do SENAIRS" e "Manual da Qualidade", em meio eletrônico. Todas estas informações, também são apresentadas por meio da exposição em quadros especiais, expostos nos setores e corredores do Departamento Regional e das Unidades Operacionais e nos eventos (cursos) realizados pelo Escritório da Qualidade SENAI. Aos clientes, os valores e diretrizes organizacionais são disseminados através da exposição em quadros expostos nos setores das unidades operacionais e através do site do SENAI. Aos fornecedores, os valores e diretrizes organizacionais são disseminados pelo edital de pré-qualificação, no site do SENAI e através de quadros expostos nos setores das unidades operacionais e do departamento regional. A verificação do entendimento dos conceitos norteadores da gestão é realizada por meio das auditorias internas e externas da NBR ISO 9001, atendimento das estratégias e indicadores de desempenho e avaliações do Programa Gaúcho da Qualidade e Produtividade (PGQP).

Cabe ressaltar que, o SENAI-RS utiliza, desde 1998, como método para o estabelecimento de padrões de trabalho, tanto da Sede do Departamento Regional como das Unidades Operacionais, os requisitos da NBR ISO 9001. A estrutura do Sistema de Gestão da Qualidade do SENAI conta com procedimentos documentados, documentos de 
referência, registros da qualidade, normas e legislação. Os padrões de trabalho, que definem como a maioria das práticas são executadas nas Unidades Operacionais (local), estão definidas em dois níveis:

a) 1 Nível: Procedimentos FIERGS; Manual da Qualidade SENAI-RS; Leis de Diretrizes e Bases da Educação;

b) 2 o Nível: Circulares SENAI-RS; Memorandos SENAI-RS; Procedimentos Regionais SENAI-RS, Procedimentos Internos das Unidades Operacionais; Rotinas padronizadas SENAI-RS, Instruções de Serviço, Organograma e Resoluções.

O Manual da Qualidade e os Procedimentos Regionais do SENAI-RS, por serem corporativos, são elaborados e revisados em conjunto, pelo Escritório da Qualidade SENAI - EQS; Gerências do Departamento Regional, conforme a especificidade de cada procedimento, e Grupo ISO (Formado por representantes dos RQ's das Unidades Operacionais). Esta união garante que as necessidades das Unidades Operacionais e das Gerências do Departamento Regional sejam consideradas dentro dos padrões. A unificação dos procedimentos no SENAI-RS iniciou em 2002 com a certificação corporativa na ISO 9001. Nas Unidades Operacionais (local), são utilizadas Resoluções, Circulares, Memorandos, Instruções de Serviço, provenientes das Gerências da sede do SENAI-RS, que orientam as atividades da unidade, sendo classificados no sistema da qualidade como "Documentos de Referência" (referência ao conjunto de documentos da qualidade - MQ e procedimentos). Estes são identificados por meio do documento "Matriz dos Documentos de Referência", que identifica o documento, versão, origem, quantidade de cópias existentes e localização. Está prática é controlada pelas auditorias da NBR ISO 9001.

Com relação à sistemática de estabelecimento dos padrões de trabalho e os métodos de controle globais, estes são coerentes com o Plano Estratégico do SENAI-RS, há interrelacionamento com as práticas de definição de ações corretivas e preventivas, bem como de revisão dos documentos do sistema de gestão da qualidade. Também há cooperação de Gerências do Departamento Regional, das Unidades Operacionais e dos Auditores Internos da Qualidade na implementação destas sistemáticas.

É importante ressaltar que dentre todas estas sistemáticas apresentadas, percebe-se que ainda existem "espaços vazios" em algumas áreas de gestão local, em Unidades Operacionais do Sistema SENAI - FIERGS. Hoje o SENAI-RS, possui um alto padrão em documentação de referência e controle de processos, controlados pelo eficiente "Escritório da Qualidade SENAI-RS", porém algumas "rotinas/sistemáticas", não são existentes para as Unidades Operacionais, ficam estas ocultas em um processo de gestão local confuso e com imensa gama de retrabalho e "stress" operacional. O principal objetivo deste artigo é demonstrar uma sistemática de apoio as Unidades Operacionais do SENAI. Esta metodologia busca conferir responsabilidades, controle e integração em células específicas de operação. Todo o detalhamento desta sistemática de gestão é apresentado na próxima seção, onde se especificam alguns dos principais processos envolvidos e suas atuais estruturas de gestão, responsabilidades e controle operacional. 
Cabe ressaltar que o trabalho de criação, avaliação e implantação desta Sistemática de Gestão Eficaz \& Sustentável - Células Integradas de Controle, foi desenvolvida durante os anos de 2011 e 2012, onde houveram os primeiros desenvolvimentos e implementações nas Unidades Operacionais do Planalto Médio (Passo Fundo, Marau e Carazinho - 2011) e finalizadas e implementadas definitivamente nas Unidades Operacionais da Serra (Bento Gonçalves, Veranópolis e Nova Prata - 2012). Junto à apresentação desta sistemática de gestão, também foi realizada uma pesquisa, durante o final do ano de 2012, para avaliar os níveis de satisfação e resultados práticos destas novas sistemáticas de gestão. Nas seções a seguir, serão apresentados detalhadamente todos os dados relativos à pesquisa aplicada nas Unidades Operacionais do SENAI na Serra Gaúcha.

\subsection{A Sistemática de Gestão - Redes de Células Integradas de Controle}

Apresenta-se neste item, uma "base" do que é a Sistemática de Gestão Eficaz \& Sustentável, controlada por células integradas, desenvolvida nos anos de 2011 e 2012, e aplicada as Unidades Operacionais da "Gestora do Planalto Médio" (Passo Fundo, Marau e Carazinho) e "Gestora da Serra" (Bento Gonçalves, Veranópolis e Nova Prata) do SENAI-RS.

Dentre todas as situações verificadas durante os processos de gestão das Unidades Operacionais apresentadas, observa-se que algumas áreas internas e locais não possuem um devido controle e muito menos uma sistemática de trabalho, definindo desta forma responsabilidades e ações específicas de trabalho.

O objetivo principal desta sistemática é de organizar estas atividades operacionais e algumas de caráter estratégico e de gestão de topo. Com base em estudos realizados entre os anos de 2010 e 2012, verificou-se que o SENAI-RS não possui uma documentação de orientação específica para determinadas práticas e trabalhos locais em Unidades Operacionais.

Cabe ressaltar que a sistemática apresentada trata de assuntos relacionados diretamente as Unidades Operacionais FIERGS - SENAI, conforme apresentado em fluxograma da "Estrutura Organizacional" na Figura 2. 
Estrutura Organizacional - SENAI-RS - 01.12.2011

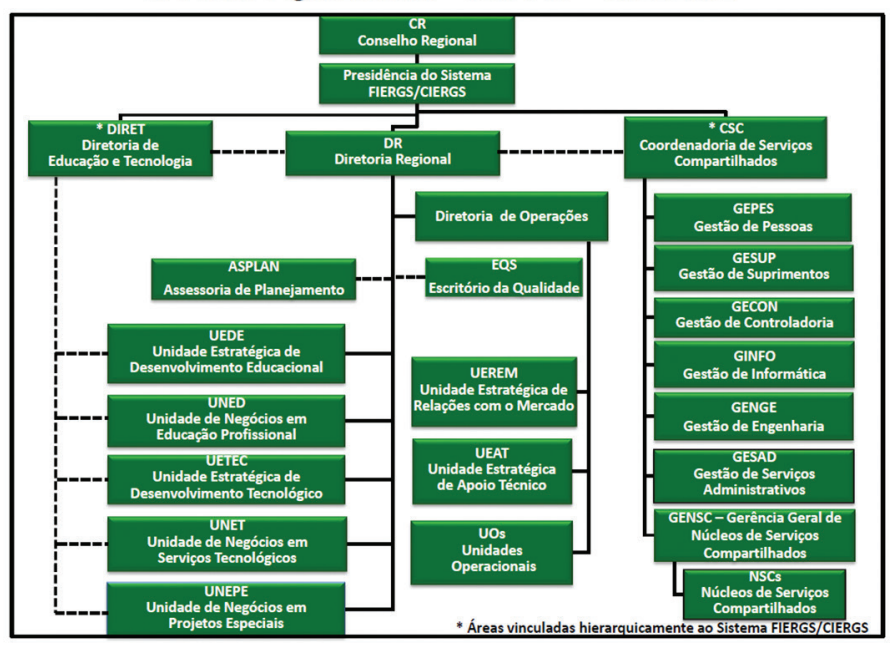

Fonte: Federação das Indústrias do Rio Grande do Sul (2013)

Conforme fundamentos teóricos específicos, verifica-se que o controle e a padronização são fundamentais para se ter eficiência, eficácia e sustentabilidade, reduzindo-se desperdícios de mão de obra, tempo e dinheiro.

\section{Segundo as interpretações de Campos (1994, p. 5), este reforça que:}

Em uma empresa que é administrada na filosofia do Controle da Qualidade, são conduzidas 03 tipos de ações gerenciais: "Planejamento da Qualidade", "Manutenção da Qualidade", "Melhoria da Qualidade". Ressalta-se que as funções operacionais ocupam muito tempo das pessoas de uma empresa e são centradas, basicamente, na "padronização". Sempre que uma pessoa exerce uma função que exige conhecimento, ela está crescendo como profissional e ser humano, agregando valor para todas as suas ações. As funções gerenciais demandam conhecimento e quanto maior o conhecimento, maiores são as possibilidades de se atingir as metas propostas. Como gerenciar é essencialmente resolver problemas e tomar decisões para se atingir metas, observa-se que para atingir as metas é fundamental se estabelecer padrões, modificar existentes ou criar novos padrões, ficando muito claro que a padronização racional é essencial para se ter eficiência e alto desempenho em gestão. Para se criar um padrão é necessário escolher uma área da empresa que não está bem, definir os problemas desta área e para cada problema localizado, definir um item de controle, planejar suas metas em um determinado período de tempo, eliminar anomalias, aplicar processo(s) de controle da qualidade e controlar os resultados, em outras palavras, organizar e padronizar o processo de gestão. As ações e verificações diárias, conduzidas para que cada pessoa possa assumir as responsabilidades no cumprimento de todas as suas obrigações são fundamentais para que haja o total entendimento do que deve ser feito por cada um dos envolvidos e em que prazo, garantindo assim a eficiência em gestão de processos. "Padrão é o instrumento que indica a meta (fim) e os procedimentos (meios) para a execução dos trabalhos; todos os gestores, em todos os níveis, para se ter otimização e resultados satisfatórios, devem estabelecer os reais e racionais padrões dos processos sob sua responsabilidade"! 
Com base no acima exposto, verifica-se a importância de processos padronizados, organizados, completos, orientados e racionais. Para que se possa ter uma impressão sobre a sistemática de gestão estudada, far-se-á um pequeno descritivo das reais dificuldades encontradas, dos estudos feitos e dos resultados esperados, tudo em concordância com os estudos acadêmicos de Campos (1994) e Kardec, Flores e Seixas (2002).

\subsubsection{As dificuldades}

Os processos Internos devem ser delegados para que todas as pessoas da organização possam contribuir com seus conhecimentos específicos e suas habilidades. Cabe ressaltar, portanto, que este estudo inicial foi realizado em um universo de $30 \%$ em uma equipe de aproximadamente 32 funcionários. No processo de gestão de pessoas e processos das Unidades Operacionais das Gestoras do Planalto Médio e da Serra, percebeu-se problemas com aproximadamente $80 \%$ do pessoal estudado, com relação às atribuições que lhe são delegadas (responsabilidades); $50 \%$ destas não entendem porque devem fazer, 30\% destas não tem "histórico" disso, nunca fizeram e 20\% querem participar, mas "não querem mais trabalho". O problema principal se resume basicamente em que aproximadamente $90 \%$ de todos os envolvidos nos estudos, se "confundem" com as informações que são repassadas para que suas atividades sejam realizadas com sucesso e dentro dos prazos. Acreditam que recebam uma quantidade enorme de informações (comunicações internas, documentação, circulares, memorando, entre outros) e não sabem direito o que fazer com elas. Todo esse processo gera aumento muito grande nos prazos de retorno interno, gerando um custo adicional da ordem de mais de $25 \%$ em reuniões desnecessárias, excesso de telefonemas, despesas com luz, água, telefone e deslocamento de pessoal e veículos das unidades, viagens desnecessárias, treinamentos desfocados para profissionais errados, entre outros.

\subsubsection{Os estudos}

Com base em todas as verificações acima citadas, o questionamento que deve ser feito é: Quais as sistemáticas, práticas e metodologias sustentáveis mais adequadas para que possa ser realizada uma otimizada delegação de atividades internas e externas, fazendo com que haja a absorção eficaz de entendimentos e informações por todos os envolvidos nos processos específicos das Unidades Operacionais da FIERGS - SENAI? Com embasamento na questão anterior, definiram-se alguns parâmetros a serem estudados junto às equipes de campo. O principal objetivo e direcionamento dos estudos é de desenvolver uma sistemática sustentável, baseada em uma metodologia de procedimentos operacionais internos eficientes e eficazes (conjunto de delegações com responsabilidades e informações otimizadas), para facilitar o entendimento do "processo de delegação de atividades com responsabilidades" e a prática mais adequada para que ocorra a "informação eficaz" para estes colaboradores. Uma sistemática sustentável, baseada em uma metodologia que possa ser repassada, em forma de "Treinamentos Internos (Coaching)". Desenvolver e implementar "Reuniões de Sustentabilidade" (com espaços para avaliações e realimentações), com uma duração máxima de 30 a 60 minutos por grupo de colaboradores envolvidos nos processos específicos (em cada uma das 
Unidades Operacionais da Gestora FIERGS - SENAI). Como detalhamento da sistemática de gestão proposta e apresentada, podem-se destacar ações realizadas em 02 níveis de complexidade:

a) elaboração de um conjunto de documentos de orientação, uma "Sistemática de Gestão Eficaz \& Sustentável", com responsabilidades e informações otimizadas, com processos básicos para todas as pessoas envolvidas nos processos internos e externos do Sistema FIERGS - SENAI;

b) dentro deste Conjunto de Documentos / Ações, criação e aplicação de um Programa PDCA ${ }_{A p s}$ (P.D.C.A. com "Aprendizado em ciclo Sustentável"), utilizando-se reuniões (Reunião de Sustentabilidade, com duração máxima de 30 a 60 minutos), para se realizar Planejamentos Estratégicos para cada área (Momentos das Responsabilidades), Ações (Treinamentos Internos e Externos), Avaliações (Reunião de Avaliações e Resultados) e os devidos ajustes / correções / realimentações (com o apoio e aceite de todos os envolvidos). Em todo este processo deve haver um Aprendizado, em ciclo Sustentável, dos planejamentos e das ações. Dentro deste ambiente de aprendizado de gestão participativa, a criação de "Reuniões de Sustentabilidade", com local e data definidos, onde são realizados os "treinamentos / informações" locais para as pessoas envolvidas, é muito importante. Nesta etapa, programou-se um MAF - "Momento de Avaliação / Feedback" para criar um aprendizado nas ações até então realizadas. O desenvolvimento e criação de uma sistemática para "novas ideias" é uma importante ferramenta para apoio e participação de todos os colaboradores envolvidos nos processos. Junto a isso a prática de um procedimento que incentive os colaboradores a se manifestar com ideias novas, sugestões "fora da caixa", apresentando soluções e novas alternativas para o desenvolvimento de toda a equipe e organização (Unidades Operacionais FIERGS - SENAI). Diante de todo este universo documental, ainda pode-se citar alguns "processos / controles" desenvolvidos: "Lista Mestra de Responsabilidades", "Controle de Unidades Móveis", "Controle da Frota de Veículos", "Controle de Atividades e Cursos Externos", "Controle de Reuniões da Gestora", "Controle de ATAS de Reuniões da Gestora", "Cursos Abertos ao Público", "Relatório de Ações Sociais Locais", "Relatório e Controle de Visitas a Empresas da Região", "Eventos, Festas e Aniversariantes da Gestora da Serra”, "Relatório e Controle de Ociosidade de Salas, Oficinas e Laboratórios na UO", "Controle de Patrimônio", "Relatório de Boas Práticas", "Relatório de Coaching em Treinamentos", "Relatório do Jornal Tô Sabendo", "Relatório de Novas Ideias", "Relatório de Ideias Fora da Caixa", "Relatórios de Sustentabilidade", "Relatório de Apoios e Parcerias".

São mais de 30 documentos oficiais e locais, similares aos que são apresentados como exemplos na seção a seguir, que retratam praticamente todas as atividades de risco ao erro e ao retrabalho. A "Lista Mestra de Responsabilidades" oficializa em forma de fluxos, todos os processos e controles, todas as responsabilidades e seus 
respectivos profissionais envolvidos, dentro do processo realizado nas UOs da Gestora. É importante frisar que esta documentação é revisada todos os meses por profissional habilitada e destacada na Gestora da Serra. Cada processo, basicamente, está definido o fluxograma de processo e controle, que determina um fluxo de controle e tomada de decisão estratégica. Conforme apresentado na próxima seção, os fluxos de ações envolvem diversos profissionais, levando-se em conta suas atividades locais e suas reais habilidades. Na falta de algum dos profissionais durante a execução de certo processo, outro logo assume, com base no fluxo, sempre baseado nas responsabilidades verticais. Cabe ressaltar que todas as informações, sempre, percorrem o fluxo de cima para baixo e as tomadas finais de decisões, sempre, ocorrem de baixo para cima, portanto, todos participam das decisões que afetam seus trabalhos locais nas UOS.

\subsubsection{Os resultados}

O projeto da sistemática em questão visa à busca por alto desempenho em gestão de processos e pessoas. Os resultados esperados são diversos, todos envolvidos com o ganho na redução de retrabalhos e aumento de eficácia dos processos organizacionais locais:

a) controle de processos e registros oficiais: Sabe-se que o controle de processos e registros destas operações é fundamental para se gerenciar uma organização com alto desempenho em sistemas. Esta sistemática de gestão trata de diversas áreas prioritárias e de grande importância para as UOs, garantindo com total controle, registros importantes em determinadas operações, ótimos resultados financeiros e o cumprimento eficaz das metas estabelecidas para estes processos;

b) gestão participativa e comprometimento: Como se observa um grande controle de gestão nos processos diários das UOs, observa-se também o grande comprometimento e participação de todos os colaboradores, levando-se em conta suas atuais posições e atividades nas Unidades Operacionais. Todo o mês, um conjunto de documentos e informações são repassados para todos os colaboradores da Gestora, onde cada setor conhece as atividades dos outros setores, todos ficam sabendo do que esta acontecendo, podendo assim cooperar com "novas ideias", "ideias fora da caixa", "Jornal Tô Sabendo" (sistemáticas criadas para estes fins). A gestão participativa aumenta o comprometimento e a satisfação dos colaboradores, aumentando o desempenho geral das organizações;

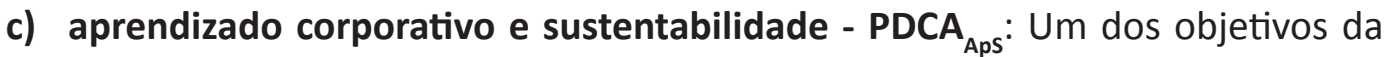
sistemáticas é a participação de todos os colaboradores em diversas atividades de suas próprias Unidades Operacionais, bem como das outras UOs da Gestora da Serra. Este "elo nas informações" proporciona uma homogeneidade nas decisões tomadas, pois erros que ocorrem em uma das Unidades Operacionais envolvidas, como aprendizado do processo, não ocorre nas outras que estão participando de mesma atividade ou processo local; 
d) distribuição de informações e garantia de entendimento: Conforme apresentado acima, as informações são disponibilizadas verticalmente de cima para baixo, onde existem processos de controle e registro destas operações. Apenas as pessoas específicas são contatadas pela Alta Direção, que dependendo do assunto, faz as informações chegarem a todas as outras partes envolvidas. Esta sistemática reduz tempo com reuniões desnecessárias, reduz o número de envolvidos que não participam do assunto tratado e garante o real entendimento do "o que fazer", "como fazer", "quando fazer" e "até quando fazer (prazos)", por parte de todos os envolvidos no fluxo (assunto) em questão.

\subsection{A sistemática de gestão: padrões de fluxos}

A seguir é apresentada, nas Figuras 3, 4, 5, 6, 7 e 8, a metodologia detalhada de alguns dos documentos, que fazem parte do universo documental da sistemática de gestão por redes de células integradas de controle. As Figuras 3 e 4 representam todas as estruturas das células integradas de controle, são expostas de forma clara e objetiva. Estas estruturas são montadas com base em sistemáticas de gestão compartilhada, onde existem definições por áreas, conforme habilidades dos profissionais envolvidos. Todos estes processos são atualizados mensalmente por profissional habilitado, prezando por informações estratégicas e operacionais que provém do Departamento Regional através de comunicados específicos.

Figura 2: Sistemática de Gestão Eficaz \& Sustentável - “Lista Mestra” (Pg. 01) - 2012

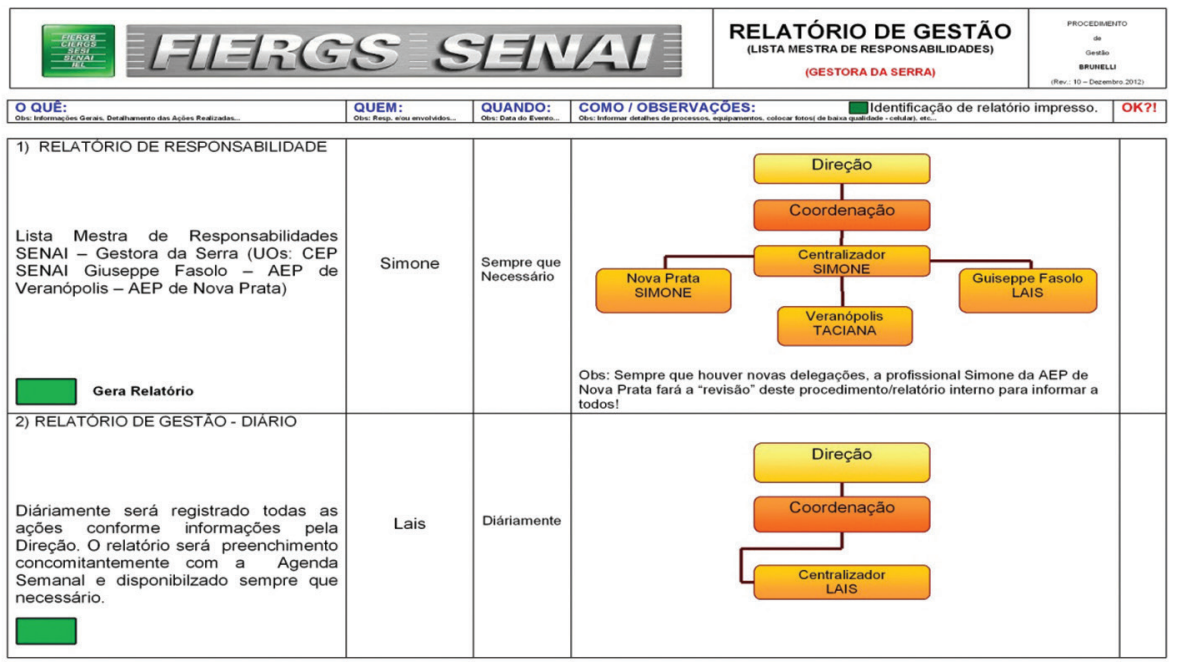

Fonte: Do autor (2012) 
Figura 3: Sistemática de Gestão Eficaz \& Sustentável - “Lista Mestra” (Pg. 02) - 2012

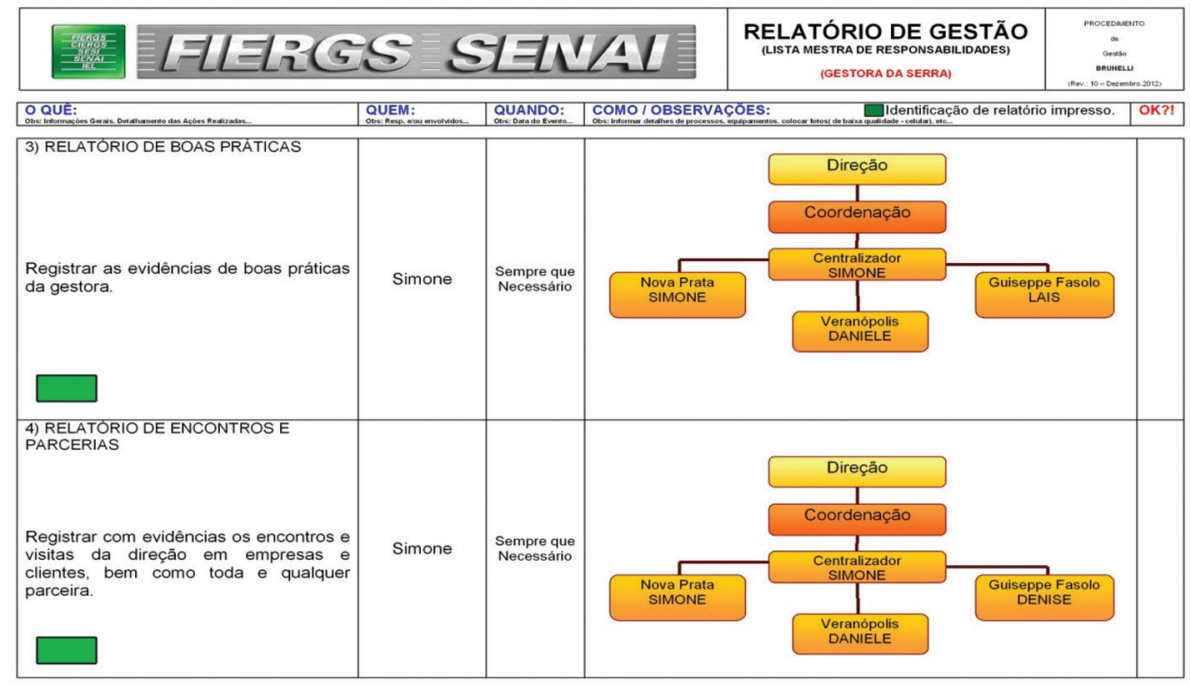

Fonte: Do autor (2012)

Nas Figuras 5 e 6, respectivamente, observa-se uma "lista mestra de atas" de reuniões realizadas durante períodos estabelecidos, dentro ou fora das unidades operacionais do SENAI e um relatório de "boas práticas", que apresentam muitas das atividades que o grupo ou unidade operacional realiza, em determinados locais e em períodos de tempo estipulados pela direção da gestora SENAI.

Similares aos documentos apresentados pelas Figuras 5 e 6 deste artigo possuem-se mais, aproximadamente, 30 documentos, que se referem, como já abordado neste trabalho, a uma série de processos que devem ter um cuidado especial. Nas Figuras 7 e 8, avaliam-se dois modelos de controle visual, que apoiam grande parte das ações de controle das redes de células integradas.

Estes documentos devem ser monitorados pela alta direção das unidades operacionais e são normalmente utilizados para tomadas de decisões estratégicas, junto ao Departamento Regional ou perante a comunidade empresarial da região em que a Unidade Operacional SENAI está inserida. Todos estes documentos e relatórios fazem parte de um complexo grupo documental, que é conhecido e apresentado neste artigo como, sistemática de gestão eficaz e sustentável (redes de células integradas de controle). 
Figura 4: Sistemática de Gestão Eficaz \& Sustentável - "Lista Mestra de ATAs" - 2012

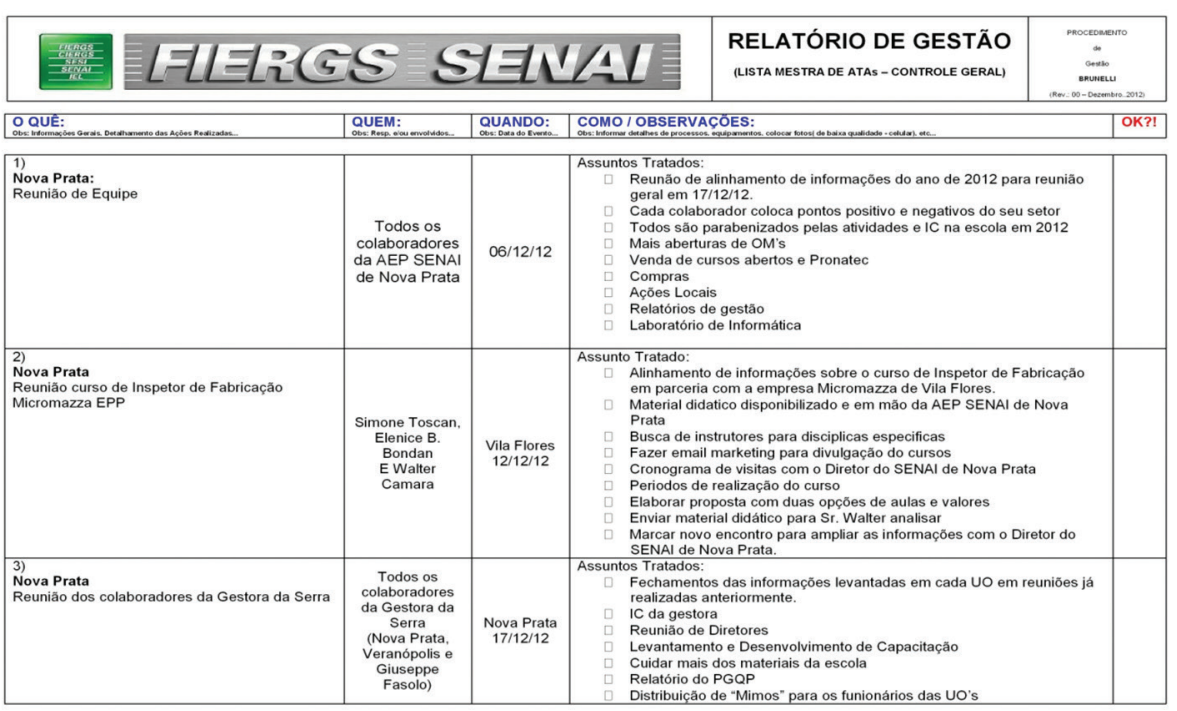

Fonte: Do autor (2012)

Figura 5: Sistemática de Gestão Eficaz \& Sustentável - "Relatório de Boas Práticas" - 2012

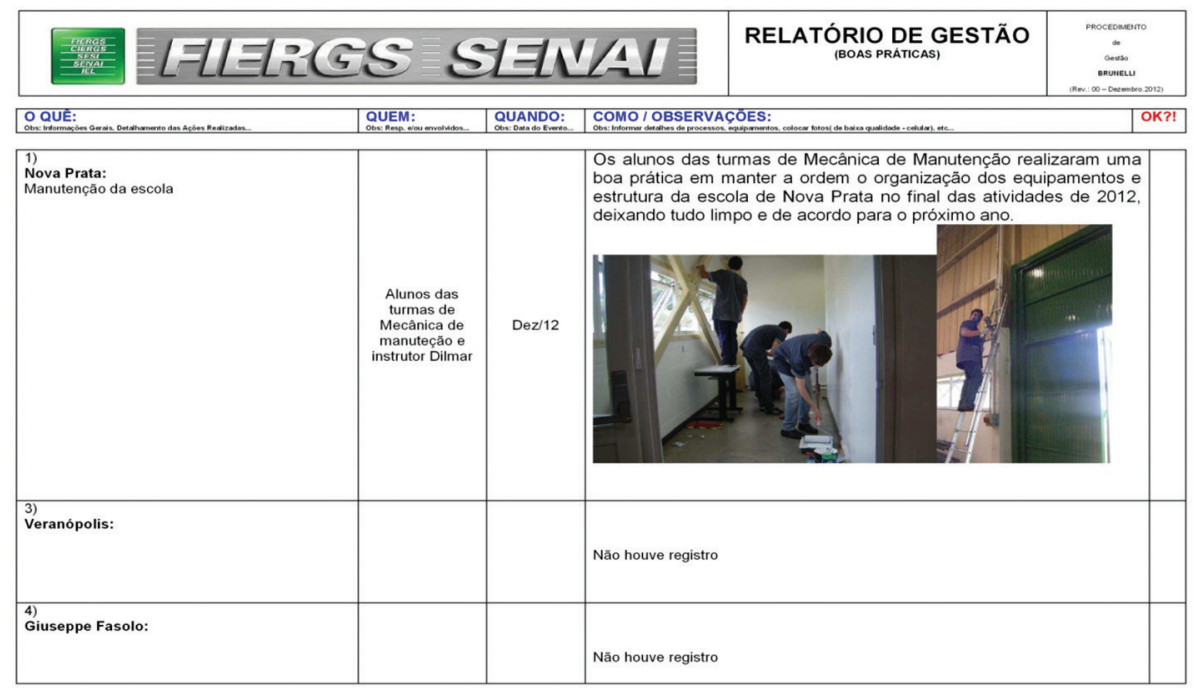

Fonte: Do autor (2012) 
Figura 6: Sistemática de Gestão Eficaz \& Sustentável - “Modelos de Controle Visual 1" - 2012

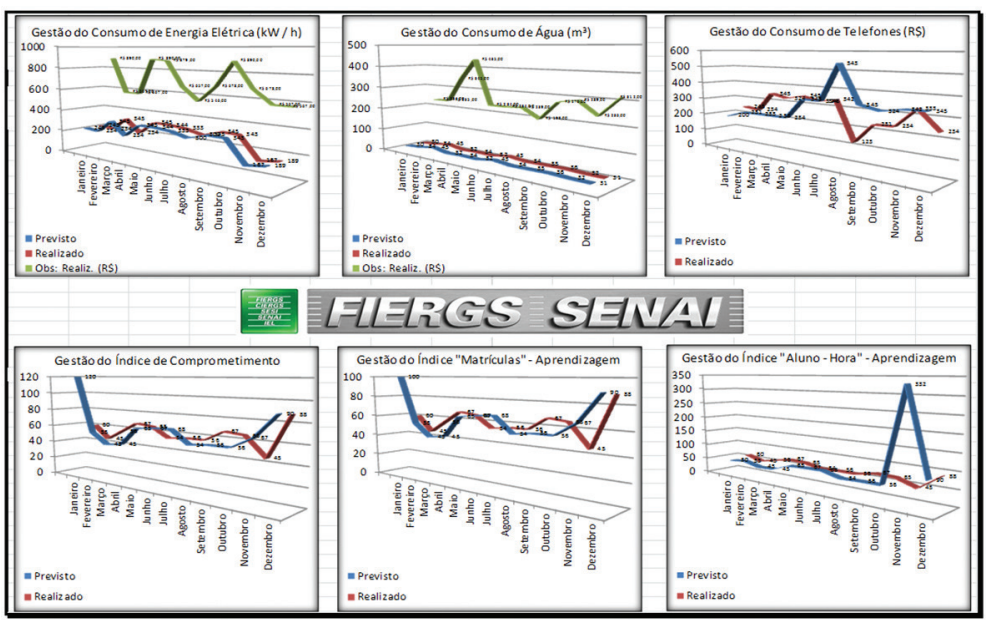

Fonte: Do autor (2012)

Figura 7: Sistemática de Gestão Eficaz \& Sustentável - “Modelos de Controle Visual 2" - 2012

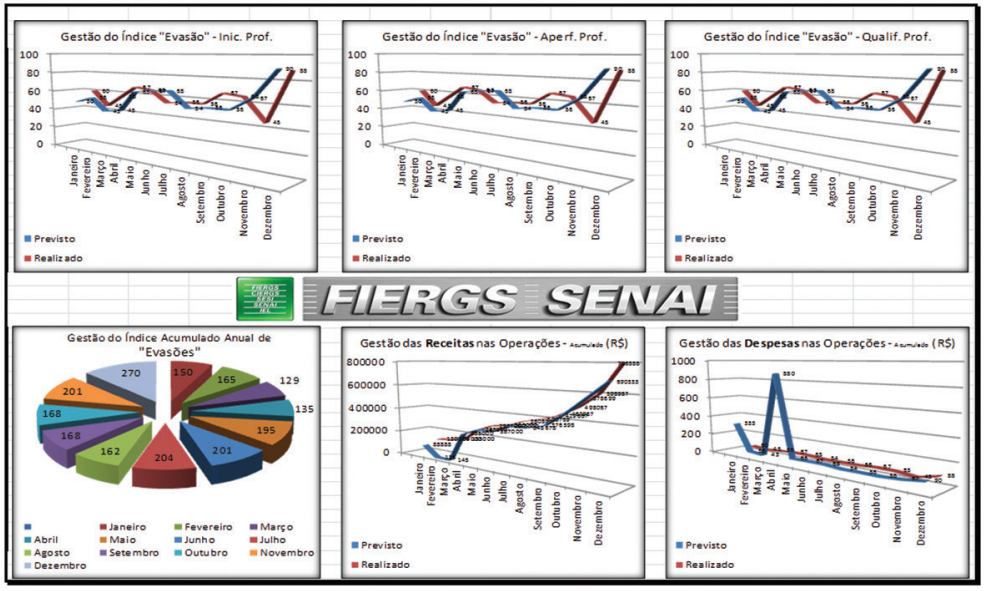

Fonte: Do autor (2012)

\section{SISTEMÁTICA DE GESTÃO EFICAZ E SUSTENTÁVEL: A PESQUISA}

Todo o trabalho desenvolvido para organizar e aperfeiçoar os processos internos das Unidades Operacionais necessitou de grande apoio dos colaboradores da Gestora da Serra. Em função desta condição, que foi essencial para que os trabalhos tivessem 
sucesso, tanto na implementação da sistemática como nos resultados obtidos, verificouse a necessidade de avaliar as condições que envolvem alguns dos profissionais que apoiaram a implementação e o atual andamento das sistemáticas de gestão. Para tanto, elaborou-se uma pesquisa sobre as sistemáticas de gestão, direcionada a um percentual dos colaboradores diretamente envolvidos das Unidades Operacionais da Gestora da Serra. O propósito básico desta pesquisa seria a investigação, em forma de dados descritivos e gráficos, de como os colaboradores "entendem e interagem" com o processo de implantação, bem como com os resultados do andamento destas sistemáticas de gestão. A pesquisa sobre os novos processos internos foi aplicada no mês de Dezembro de 2012, para um grupo de 10 profissionais (30\%) da equipe atual das Unidades Operacionais FIERGS - SENAI: CEP SENAI Giuseppe Fasolo, AEP SENAI de Nova Prata e AEP SENAI de Veranópolis. A referida pesquisa foi elaborada com 15 questões de múltipla escolha, cada uma das questões com observações específicas, para informações e respostas adicionais. Cabe ressaltar que a pesquisa desenvolvida, foi validada por profissionais capacitados, o que a tornou fidedigna aos propósitos deste estudo.

Terminada toda a interpretação dos dados expostos neste artigo, os dados serão novamente avaliados nas Unidades Operacionais da Gestora da Serra, para a verificação de futuras melhorias e mudanças racionais, em relação à atual sistemática de gestão de processos nas Unidades Operacionais da FIERGS - SENAI.

\subsection{Procedimento metodológico}

A pesquisa foi desenvolvida de modo a gerar dados, tanto quantitativos quanto qualitativos. É importante salientar que para Gil (2002), a pesquisa quantitativa é apropriada para medir tanto opiniões, atitudes e preferências como comportamentos. Por meio deste tipo de pesquisa também é possível descobrir quantas pessoas de uma determinada população compartilham uma característica ou grupo de características.

Em relação à pesquisa qualitativa, Gil (2002) aponta que fornece um processo a partir do qual questões-chave são identificadas e perguntas são formuladas, descobrindo o que importa para os indivíduos (clientes, fornecedores, colaboradores, entre outros) e o porquê.

Este tipo de pesquisa também é usado para identificar a extensão total de respostas ou opiniões que existem em um mercado ou população.

A pesquisa desenvolvida neste artigo apresenta-se principalmente como exploratória e de levantamento, também com base nos estilos descritiva e bibliográfica. Segundo Gil (2002), estes tipos de coleta de dados são determinados como pesquisa: 
a) exploratória: tem como objetivo proporcionar maior familiaridade com o problema, com vistas a torná-lo mais explícito. Pode envolver levantamento bibliográfico, entrevistas com pessoas experientes no problema pesquisado. Geralmente assume a forma de pesquisa bibliográfica e estudo de caso;

b) descritiva: tem por objetivo principal a descrição das características de determinadas populações ou fenômenos. Uma de suas características está na utilização de técnicas padronizadas de coleta de dados, tais como o questionário e a observação sistemática. Destacam-se ainda na pesquisa descritiva, aquelas que visam descrever características de grupos (idade, sexo, procedência, etc...);

c) levantamento: é a interrogação direta das pessoas, cujo comportamento se deseja conhecer, uma pesquisa de campo. Procede-se à solicitação de informações a um grupo significativo de pessoas acerca do problema estudado para, em seguida, mediante análise quantitativa, obterem-se as conclusões correspondentes aos dados coletados;

d) bibliográfica: desenvolvida com base em material já elaborado, constituído principalmente de livros e artigos científicos.

\subsection{Os resultados apurados na pesquisa}

As questões de no 01 a 15, da referida pesquisa aplicada aos colaboradores da UOs da Gestora da Serra - FIERGS- SENAI, relacionam uma coleta de informações sobre diversos temas de grande importância para os estudos realizados, e estão devidamente apresentados nos gráficos a seguir.

No gráfico 1, são apresentados dados sobre a faixa etária dos colaboradores, onde se pode verificar que a maioria, exatamente $40 \%$, está na faixa etária 31 a 40 anos de idade, o restante dividido em $20 \%$ para cada faixa. 
Gráfico 1: Faixa etária

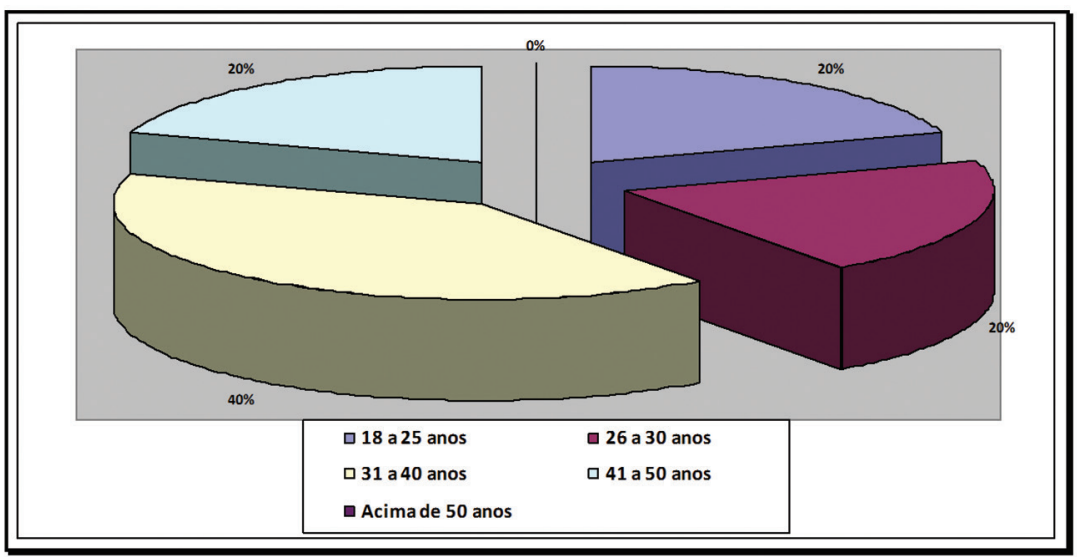

Fonte: Do autor (2012)

No gráfico 2, observam-se dados sobre a formação dos colaboradores, onde se pode verificar que exatamente $40 \%$ destes possuem formação superior, os demais estão divididos em $30 \%$ para pós-graduação, $20 \%$ para superior incompleto e $10 \%$ para ensino médio.

Gráfico 2: Formação

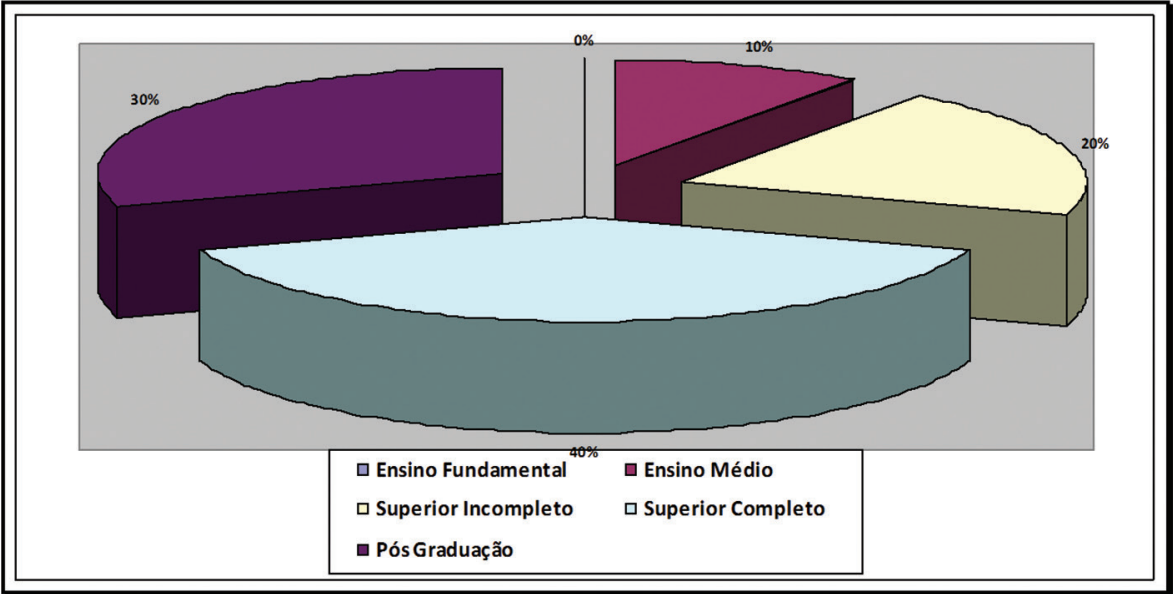

Fonte: Do autor (2012)

No gráfico 3 observa-se, que foram coletados dados sobre a área de atuação dos colaboradores, onde se verifica que a maioria, $40 \%$ destes, está na área administrativa, 0 restante está dividido em $30 \%$ para a área de educação e tecnologia, sendo que os outros $30 \%$ estão divididos em três áreas, tecnologia e serviços, qualidade e coordenação de cursos. 
Gráfico 3: Área de atuação profissional

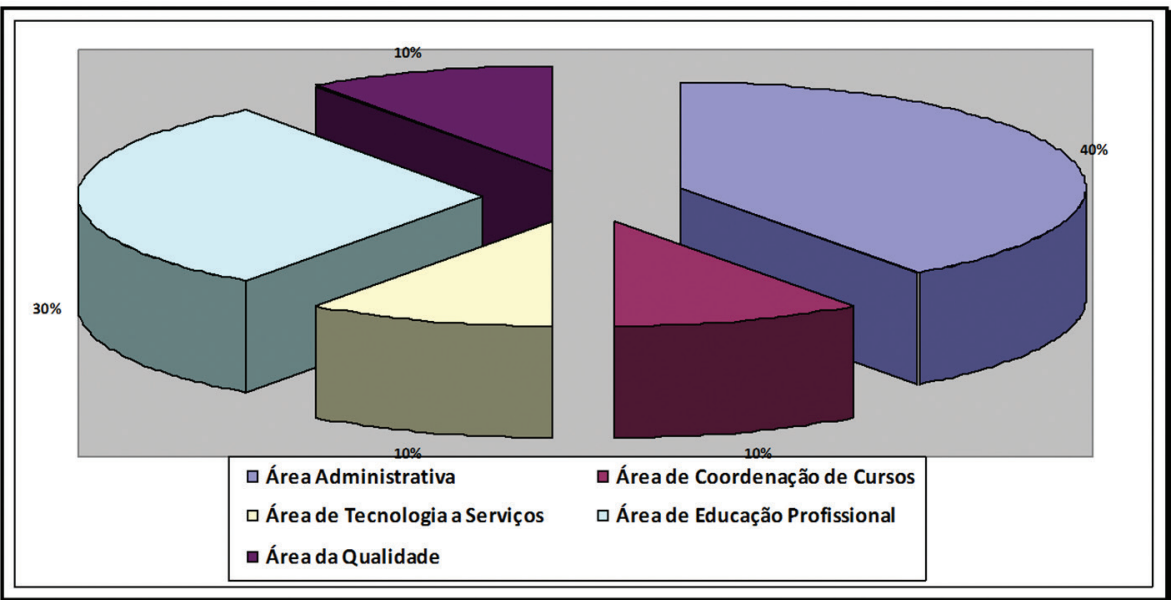

Fonte: Do autor (2012)

No gráfico 4, com relação ao tempo de casa, observa-se que a maioria, exatamente $60 \%$ destes, possui de 4 a 10 anos, o restante está dividido em $30 \%$, para os que possuem de 1 a 3 anos e os outros $10 \%$ que possuem de 11 a 20 anos.

Gráfico 4: Tempo de Casa

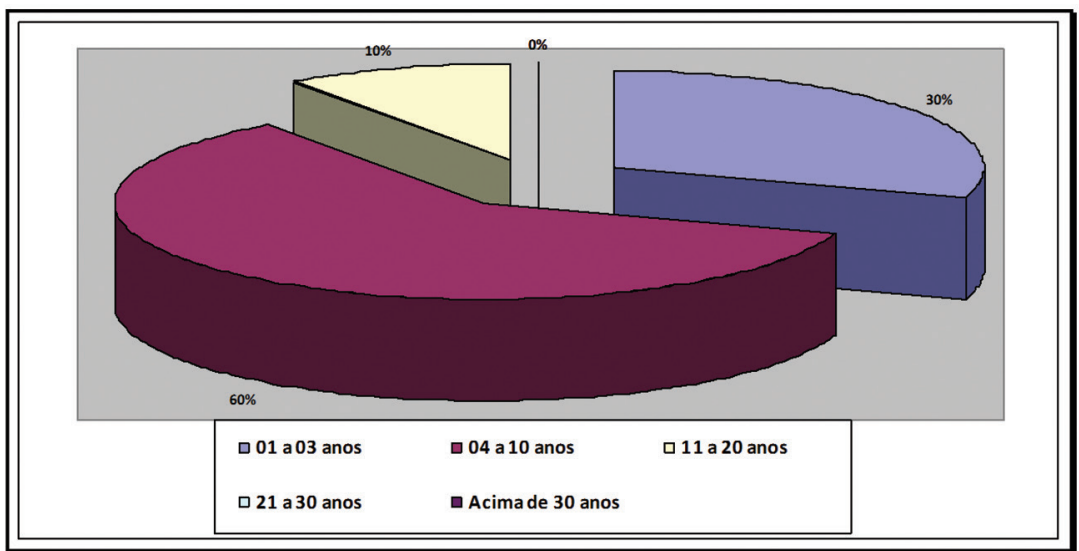

Fonte: Do autor (2012)

No gráfico 5, foram coletadas informações sobre a percepção dos processos anteriores ao ano de 2012 , onde se ressalta com importância, que a maioria exatamente $60 \%$, classifica e considera como bons, mas muito burocráticos. 
Gráfico 5: Percepções de processos anteriores ao ano de 2012

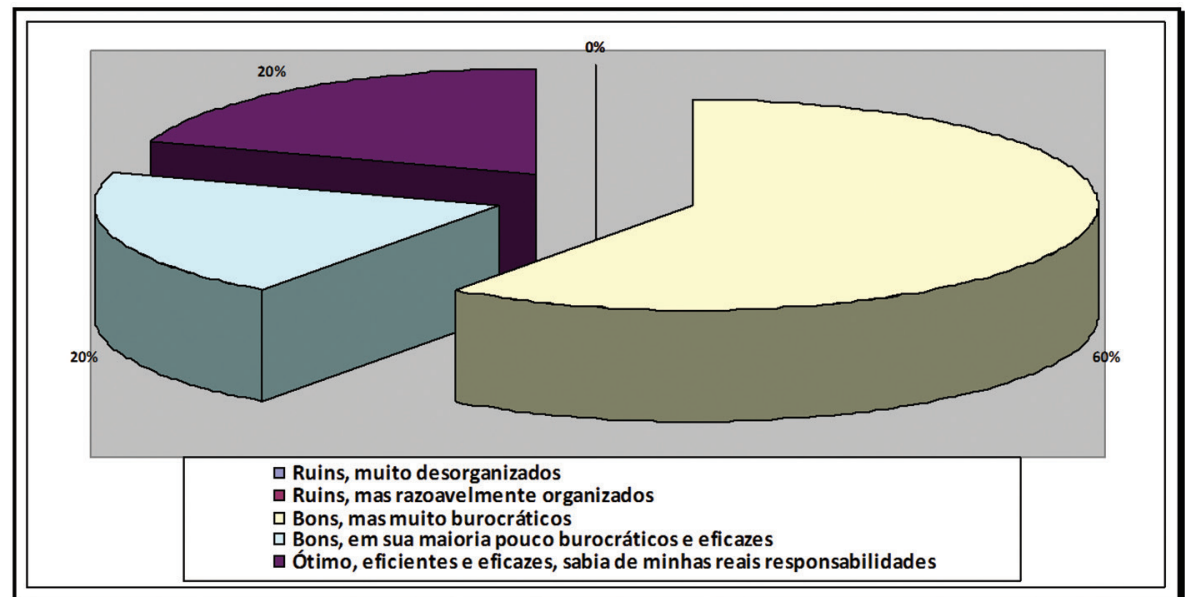

Fonte: Fonte: Do autor (2012)

No gráfico 6, com relação a satisfação dos colaboradores diante dos processos, anteriores ao ano de 2012 , percebe-se que $40 \%$ estão satisfeitos com a maioria, $40 \%$ estão satisfeitos com alguns e $20 \%$ estão insatisfeitos.

Gráfico 6: Satisfação com os processos internos anteriores ao ano de 2012

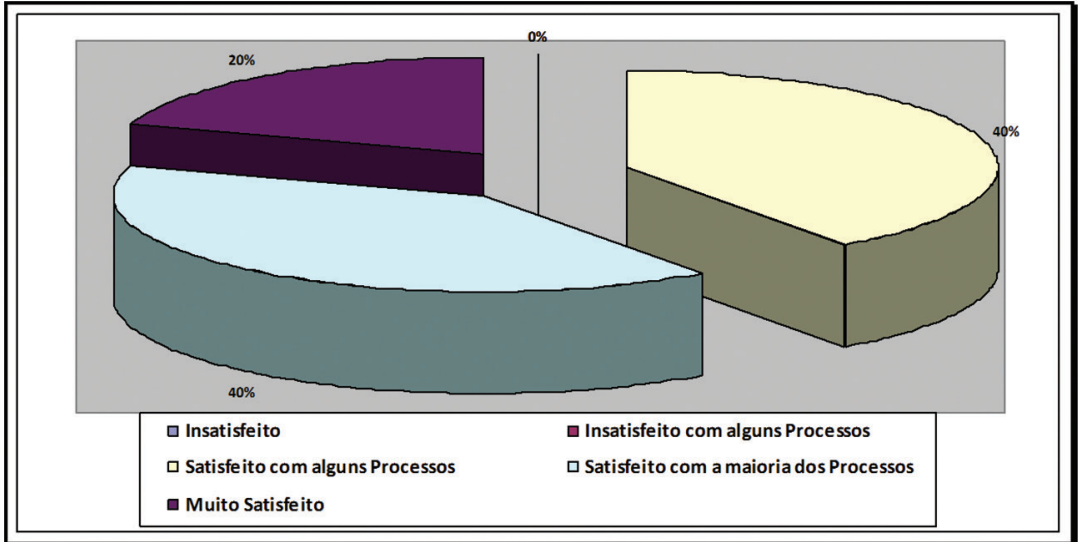

Fonte: Do autor (2012)

No gráfico 7, relativo às mudanças nos processos, anteriores ao ano de 2012, 40\% gostariam de ter mudado a maioria, 30\% gostariam de mudar alguns poucos, $20 \%$ acreditam que a maioria eram bons, porém para $10 \%$ está tudo ótimo. 
Gráfico 7: Mudanças nos processos internos anteriores ao ano de 2012

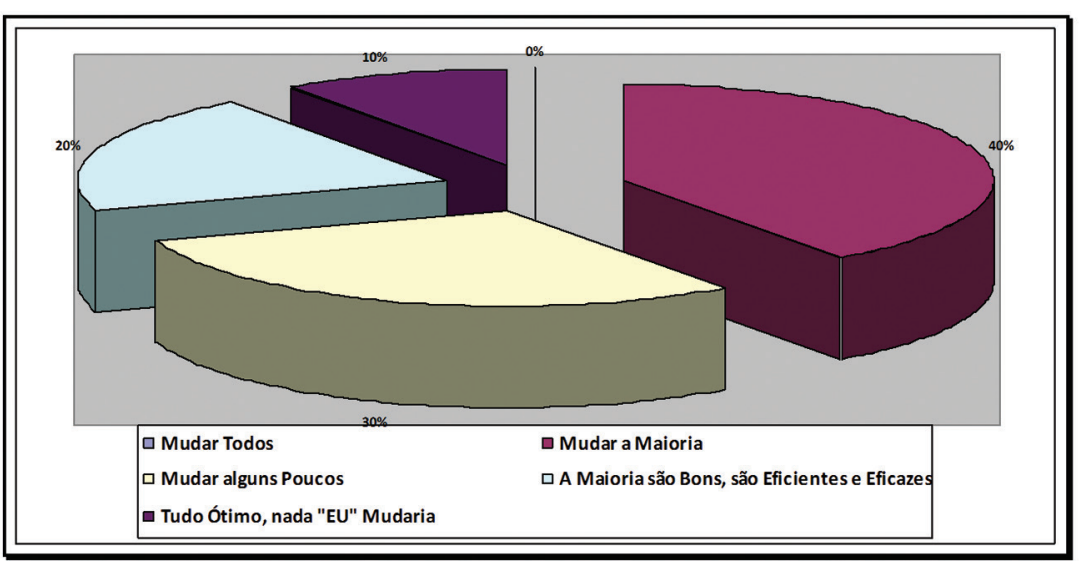

Fonte: Do autor (2012)

O gráfico 8 observa-se que a percepção dos colaboradores em relação aos processos pós Julho de 2012 se apresenta com 70\% destes, os considerando bons e eficazes, $20 \%$ bons, mas muito burocráticos e os $10 \%$ restantes, ótimos.

Gráfico 8: Percepções de processos internos posteriores a Julho de 2012

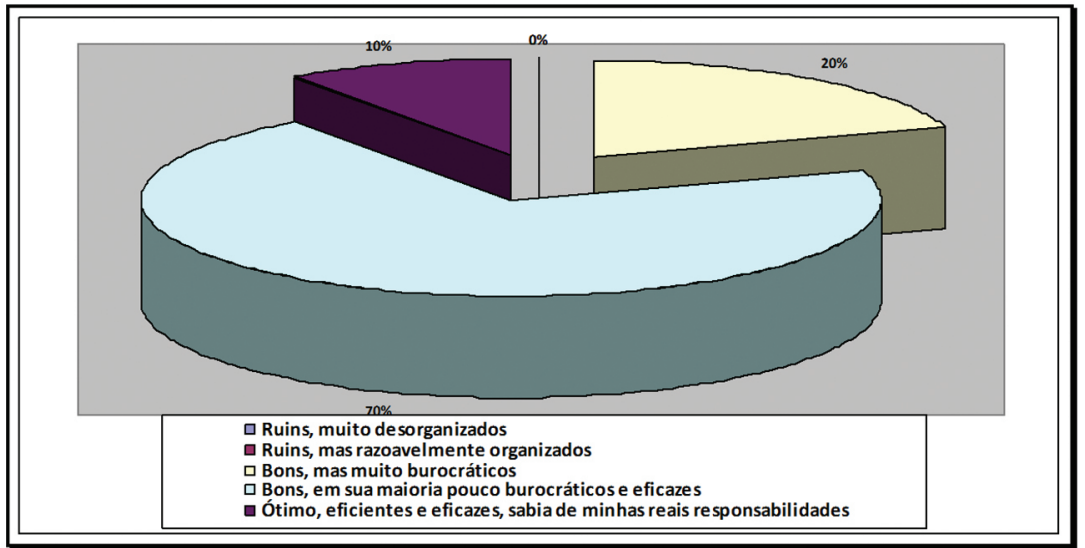

Fonte: Fonte: Do autor (2012)

No gráfico 9, relativo ao nível de satisfação com os processos internos, posterior a Julho de 2012 se apresenta com 70\% destes satisfeitos com a maioria e os 30\% restantes, divididos em muito satisfeitos, satisfeitos e insatisfeitos. 
Gráfico 9: Satisfação com os processos internos posteriores a Julho de 2012

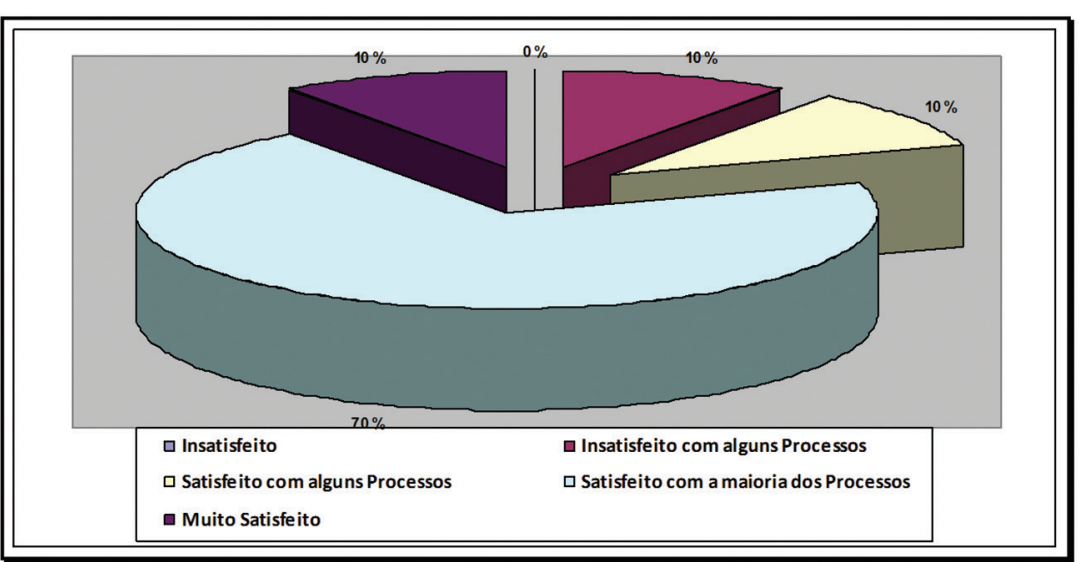

Fonte: Do autor (2012)

No gráfico 10, com relação às mudanças nos processos posteriores a Julho de 2012, verifica-se que $50 \%$ dos colaboradores gostariam de mudar alguns, $40 \%$ os consideram bons, são eficientes e eficazes e $10 \%$ consideram tudo ótimo.

Gráfico 10: Mudanças nos processos internos posteriores a Julho de 2012

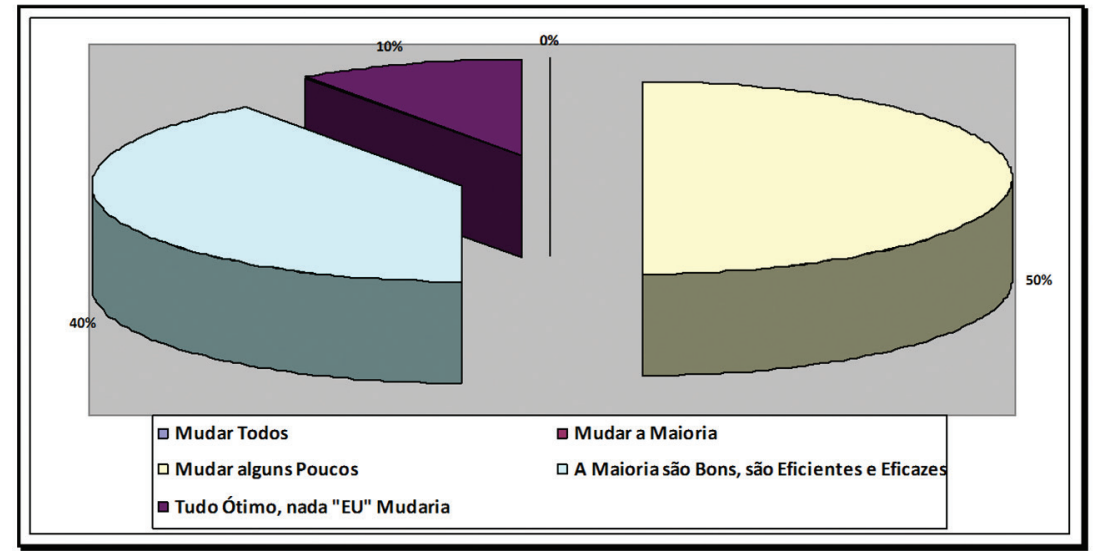

Fonte: Do autor (2012)

No gráfico 11, avaliando-se a área de maior concentração de dificuldades, pode-se notar que a maioria, $80 \%$ dos entrevistados, afirmam que é a área administrativa, $20 \%$ restantes estão divididos nas áreas de educação e tecnologia. 
Gráfico 11: Área de concentração de dificuldades nos processos internos

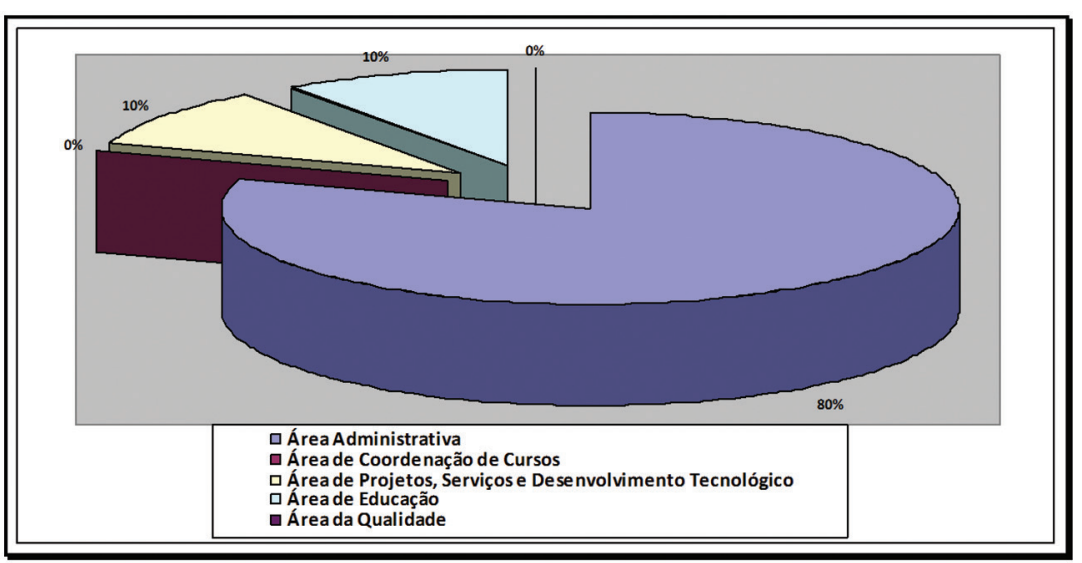

Fonte: Do autor (2012)

No gráfico 12 , com relação à otimização de processos por áreas, verifica-se que $70 \%$ dos entrevistados, modificariam os da área administrativa, o restante modificaria a área de coordenação, qualidade e de projetos e serviços.

Gráfico 12: Área para otimização de processos de gestão

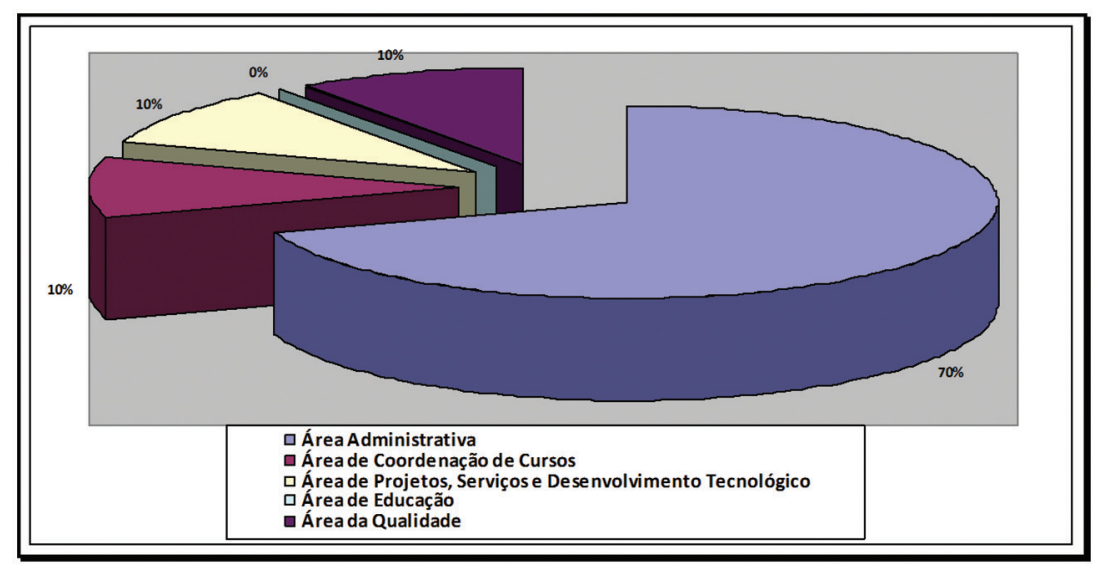

Fonte: Do autor (2012)

No gráfico 13, coletaram-se dados sobre o que cada entrevistado faria na área de maior dificuldade. A maioria, exatamente $70 \%$, alteraria alguns dos processos na área e $30 \%$ restantes fariam documentos de apoio a estes processos. 
Gráfico 13: O que "EU" faria na área de maior dificuldade

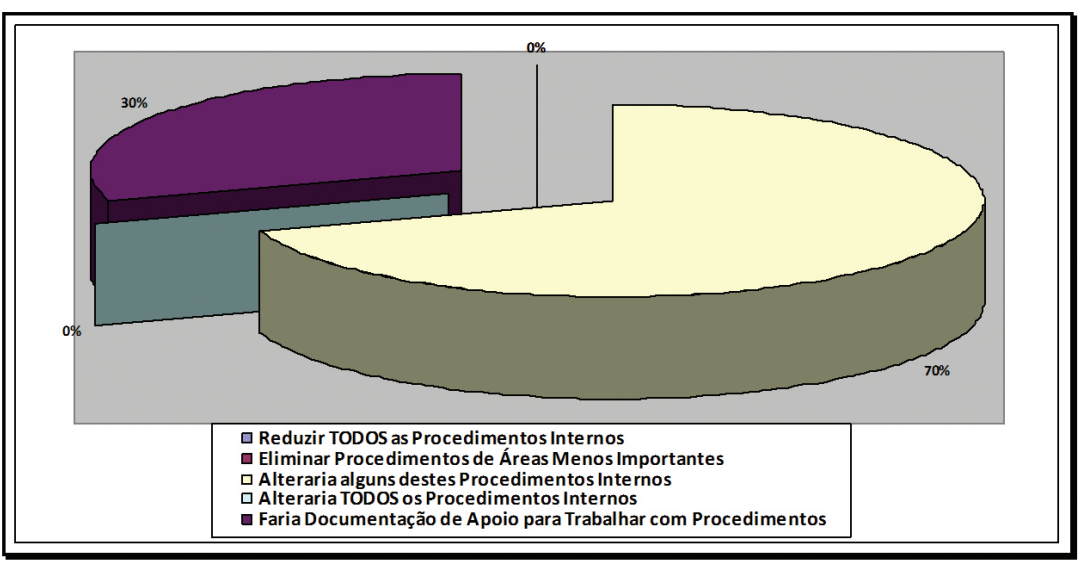

Fonte: Do autor (2012)

No gráfico 14, observa-se com relação à participação no projeto da nova sistemática, que a maioria, 70\%, apreciaram, cooperando com sugestões, $20 \%$ acreditam não haver nada a ser mudado e $10 \%$ não gostaram de participar.

Gráfico 14: Sugestão e participação na nova sistemática de gestão

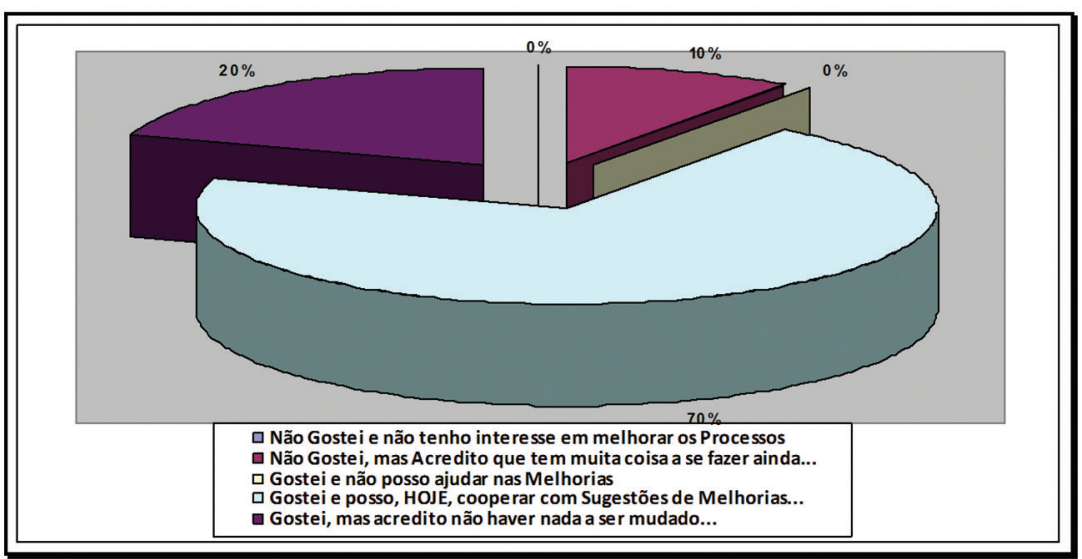

Fonte: Do autor (2012)

E por fim, no gráfico 15, avaliando-se a satisfação em relação à nova sistemática de integração, percebe-se que $60 \%$ gostaram e hoje podem entender e contribuir, os outros $40 \%$ gostaram muito e querem continuar interagindo. 
Gráfico 15: Satisfação e integração com a nova sistemática

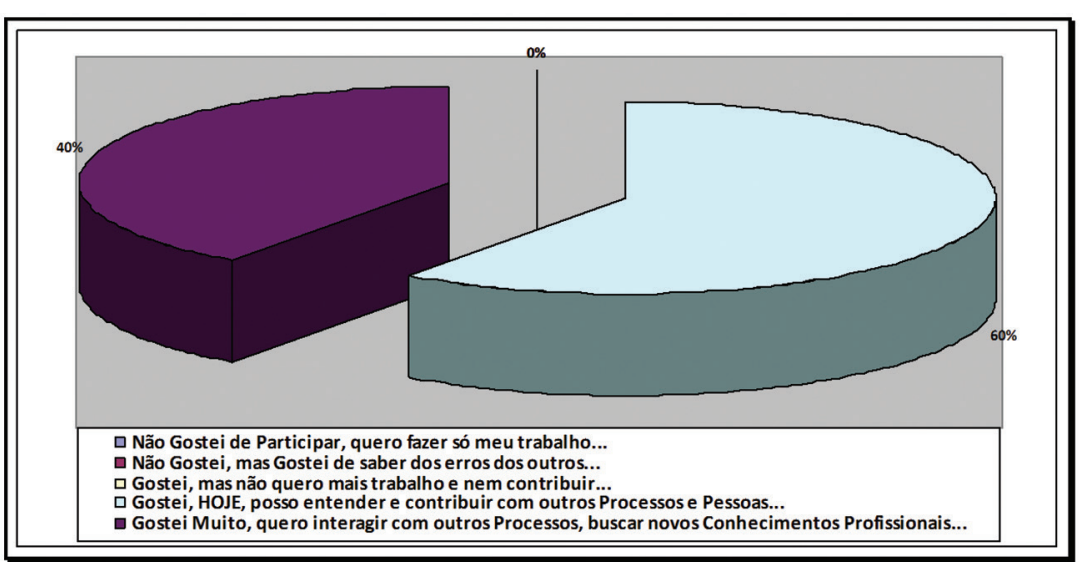

Fonte: Do autor (2012)

\subsection{Análise e tratamento dos dados da pesquisa}

Após a obtenção de dados, com base nos entrevistados das Unidades Operacionais SENAI, elaboram-se algumas análises, que reforçam a ideia principal deste artigo.

As primeiras informações referem-se basicamente a idade dos entrevistados, tempo de casa, formação e área de atuação nas Unidades Operacionais. Percebe-se que todos os entrevistados possuem idade e escolaridade que certificam tomadas de decisões de porte diretivo. Estes fatores reforçam a importância de suas ações e opiniões com relação à nova Sistemática de Gestão. Junto a estes fatores, verifica-se que os entrevistados possuem tempo de casa considerado pequeno, isto facilita a busca por informações e respostas sem o "vício" em processos, que o grande tempo de casa pode vir a causar. Foram selecionados colaboradores de áreas diversas, mas que estão intimamente ligados a nova Sistemática de Gestão, podendo estes opinar de forma coerente aos objetivos deste artigo.

Ao final do levantamento de dados individuais, referentes às condições atuais de cada entrevistado, buscou-se reforçar opiniões sobre os processos internos anteriores ao ano de 2012. Uma das funções desta pesquisa era colher informações sobre o "real sentimento" dos profissionais entrevistados, conforme se apresentam nos gráficos anteriores, coletar as impressões e as satisfações perante as sistemáticas de processos internos que vinham sendo realizadas. Cabe ressaltar que houve respostas firmes e claras, que demonstravam através de números, que os processos internos estavam muito burocráticos, pouco eficientes e eficazes, isto quando existiam processos para certas áreas, pois determinadas áreas estavam sem processos de controle e integração. Os níveis de satisfação em se trabalhar desta forma, sugerem mudanças rápidas para se obter o desempenho esperado. Como resposta dissertativa, obteve-se de um dos entrevistados o seguinte relato, "a forma como os processos estavam sendo realizados não é ruim, mas precisa urgentemente ser atualizada para outros níveis de integração, 
eficiência e desempenho corporativo". Percebe-se que todos os entrevistados possuem opiniões similares a respeito da sistemática de processo que vinha sendo realizada até meados do inicio do ano de 2012.

Como o objetivo desta pesquisa também era de comparar sistemáticas de processos em diferentes períodos de tempo, perguntas de igual teor às realizadas para o período anterior ao ano de 2012, foram aplicadas para o período posterior a Julho de 2012. É importante destacar que toda sistemática de processos apresentada neste artigo, foi inicialmente colocada em prática neste período de Julho de 2012. Como esta pesquisa foi realizada ao final do ano de 2012, tem-se assim um bom tempo de absorção das novas práticas de operações desenvolvidas.

Observa-se que todos os entrevistados possuem um alinhamento nas respostas, quanto a sua satisfação, cooperação, aplicabilidade e seus possíveis problemas na operação da nova sistemática de processos. Ressaltam-se os dados da satisfação em trabalhar com um conjunto de novas ações que agilizam todos os processos envolvidos, que aperfeiçoam recursos e que facilitam o entendimento real das operações a serem realizadas por cada colaborador. Houve, em uma das respostas dissertativas, um comentário muito importante, "existe um novo alinhamento de ações, uma nova integração de áreas, redução de retrabalhos e desperdícios, existe um aprendizado em todos os processos, evitando perdas de tempo e de mão de obra especializada, sabe-se o que cada um tem que fazer, quando fazer e de que forma fazer". Também com um grande alinhamento de opiniões, observa-se que a área administrativa se apresenta com o maior grau de dificuldade de entendimento, sincronismo e operação local. Torna-se assim alvo das maiores mudanças realizadas e requisitadas, conforme se observa nos gráficos apresentados.

Um importante ponto a ser avaliado nesta pesquisa, fica determinado pelo sentimento de participação dos colaboradores entrevistados, no desenvolvimento e aplicação da nova sistemática apresentada neste artigo. De simples entendimento, conforme apresentam os gráficos e os apontamentos do capítulo anterior, observa-se um total sincronismo da equipe, uma forte sensação de estar cooperando, fazendo parte de um novo processo, que certamente facilitará todas as operações nas UOS SENAI. Todos os entrevistados, mesmo com diferenças de idade, tempo de casa, funções e conhecimentos, alinharamse em um mesmo pensamento, uma mesma forma de satisfação em participar, em fazer a diferença para otimizar. Existe, com base em relatos dissertativos, uma sensação de crescimento profissional, pois a sistemática integra muitas áreas entre si, fazendo com que todos os envolvidos obtenham novos conhecimentos nas mais diversas operações SENAI - FIERGS. 


\section{CONCLUSÕES}

Ao final de diversas análises relacionadas aos processos internos, suas sistemáticas de operação, suas dificuldades de implementação, estudos de otimização de processos e resultados esperados, buscou-se levantar informações e oportunidades de melhoria para que haja um sincronismo de adaptabilidade das Unidades Operacionais FIERGS SENAI a proposta deste artigo.

Percebe-se que é muito importante que se possa ter processos enxutos, racionais e eficazes para todas as áreas de operações. Para as organizações SENAI - FIERGS observa-se que existem alinhamentos profissionais que regem todas as diversas operações da organização, desde a alta direção até as Unidades de Operação Local. Todos estes processos desenvolvidos até hoje, na organização SENAI - FIERGS, não apoiam eficazmente as atividades essencialmente rotineiras e locais, de controle e de entendimento para operação, enfim, não existem sistemáticas de caráter operacional, voltados para atividades rotineiras nas UOS.

Este artigo apresenta as reais dificuldades encontradas nas Unidades Operacionais, os estudos realizados para a adequação com eficácia e os resultados esperados. Cabe ressaltar que dentre todos os aspectos aqui elencados, tratados e apresentados, a questão "resultados obtidos" é muito importante.

Após a implementação da sistemática de processos, com células integradas de controle nas UOs SENAI - FIERGS, percebe-se que houve um grande aumento da eficiência nas operações rotineiras, ocorreu um aumento considerável no desempenho das pessoas envolvidas com as atividades rotineiras e uma melhora significativa nos índices de receitas, com redução acentuada nos índices de despesas operacionais das Unidades Operacionais SENAI - FIERGS.

Acredita-se que a sistemática aplicada aos processos das UOs, trouxe uma nova integração entre as áreas, uma nova sensação de comprometimento das pessoas, uma grande satisfação de poder entender o trabalho executado. Saber como fazer, quando fazer, o jeito de fazer e seus prazos torna o trabalho prazeroso, rentável e eficiente, pessoas motivadas rendem muito mais em suas atividades.

Vários são os pontos e sistemas apresentados neste trabalho, que estes sirvam como base para apoiar novas pesquisas e a formatação de um "plano de ação", objetivando-se a implantação destas sistemáticas de processos por células integradas de controle, em toda a rede da organização FIERGS. 


\title{
SYSTEMATIC OF EFFECTIVE AND SUSTAINABLE MANAGEMENT CELL INTEGRATED NETWORK CONTROL
}

\begin{abstract}
The success of organizations depends largely on the motivation and commitment that all employees have. It is essential that one can understand some of the difficulties that reduce the degree of commitment, satisfaction, and efficiency in performed operations, thus seeking specific information and applied studies, thus developing, new resultsbased management practices. The article in question presents new solutions for the management of operational activities in Units of Education and Technology Senai - FIERGS aimed mainly at the implementation of systematic management cell-based integrated control. Each cell represents a certain area of local activities, integrated and controlled in a rational and effective way. In this article are also presented, results of a satisfaction survey and technical cooperation, related to the new system of management, parameters, these, that indicate new understandings, actions and results. In the development of this article, that is a case study, are offered in a rational way, a number of opportunities and suggestions for improvements in many of the areas of greatest impact on educational, technical and technological operations and results of Senai - FIERGS units.
\end{abstract}

Keywords: Management. Integrated Control cells. Sustainability

\section{REFERÊNCIAS}

AAKER, D. A. Administração estratégica de mercado. 7. ed. Porto Alegre,RS: Bookman, 2007.

ANSOFF, IGOR H. Implanting Strategic Management. USA. Englewood Cliffs, N. J.: Prentice - Hall, 1984. 
BOWER, M. The Will to Manage: corporate success through "programmed management". USA, New York: McGraw - Hill, 1986.

CAMILOTI, L. Liderança organizacional. Florianópolis, SC: SENAI /SC, 2010.

CAMPOS, V. F. Gerenciamento da rotina do trabalho do dia-a-dia. Belo Horizonte: Fundação Christiano Ottoni, Escola de Engenharia da UFMG. Rio de Janeiro, RJ: Bloch, 1994.

CERTO, S. C.; PETER, J. P. Administração estratégica: planejamento e implantação da estratégia. São Paulo, SP: Pearson Education do Brasil, 1993.

CHIAVENATO, I. Planejamento, recrutamento e seleção de pessoal: como agregar talentos à empresa. 7. ed. Barueri, SP: Manole, 2009a.

. Recursos Humanos: o capital humano das organizações. 9. ed. Rio de Janeiro,RJ: Campus, 2009b.

DESCHAMPS, F. Gestão da inovação. Florianópolis, SC: SENAI /SC, 2011.

DRUCKER, P. F. Sociedade pós-capitalista. São Paulo, SP: Pioneira, 1994.

FARIA, J. H. Gestão Participativa: relação de poder e de trabalho nas organizações. São Paulo, SP: Atlas, 2009.

FARIAS, J. R. de V. Organizações Coletivistas de Trabalho: autogestão nas unidades produtivas. 2003. 229 f. Dissertação (Mestrado em Administração) - Universidade Federal do Paraná, Curitiba, 2003.

FÁVARO, E. V. Gestão de pessoas. Florianópolis, SC: SENAI/SC, 2011.

FEDERAÇÃO DAS INDÚSTRIAS DO RIO GRANDE DO SUL. SERVIÇO NACIONAL DE APRENDIZAGEM INDUSTRIAL. Conjunto de informações e procedimentos nas áreas de educação e tecnologia. Porto Alegre, RS, 2013.

GIL, A. C. Como elaborar projetos de pesquisa. 4. ed. São Paulo, SP: Atlas, 2002. 
GINTER, P. M.; WHITE, D. D. A social learning approach to strategic management: toward a theoretical foundation. USA. Academy of Management Review, 1982.

GLAVAM, R. B. Gestão estratégica de instituições de educação profissional e de serviços técnicos e tecnológicos. Florianópolis, SC: SENAI /SC, 2010.

KARDEC, A.; FLORES, J.; SEIXAS E. Gestão estratégica e indicadores de desempenho. Rio de Janeiro,RJ: Qualitymark: Abraman, 2002.

MARTINS, C. F.; RASCHE F. Orientação ao TCC. Florianópolis, SC: SENAI /SC, 2010.

PUA, K.S. ; DEBBIE Y. Y. H. Rumo ao Sucesso: a jornada de US\$ 1 Bilião da Phison, a Estrela da Tecnologia. Instituto Euvaldo Lodi - IEL. Porto Alegre, RS: AGE, 2012.

RAMOS, A. G. Administração e contexto brasileiro: esboço de uma teoria geral da administração. Rio de Janeiro, RJ: Editora da FGV, 1983.

ROCK, R. H. ; EISTHEN M. Implementing strategic change. USA, New York: McGrawHill, 1983.

UM GUIA do conjunto de conhecimentos em gerenciamento de projetos: guia PMBOK. 3. ed. Newtown Square, PA: Project Management Institute, c2004. ix, 388 p.

\section{SOBRE O AUTOR}

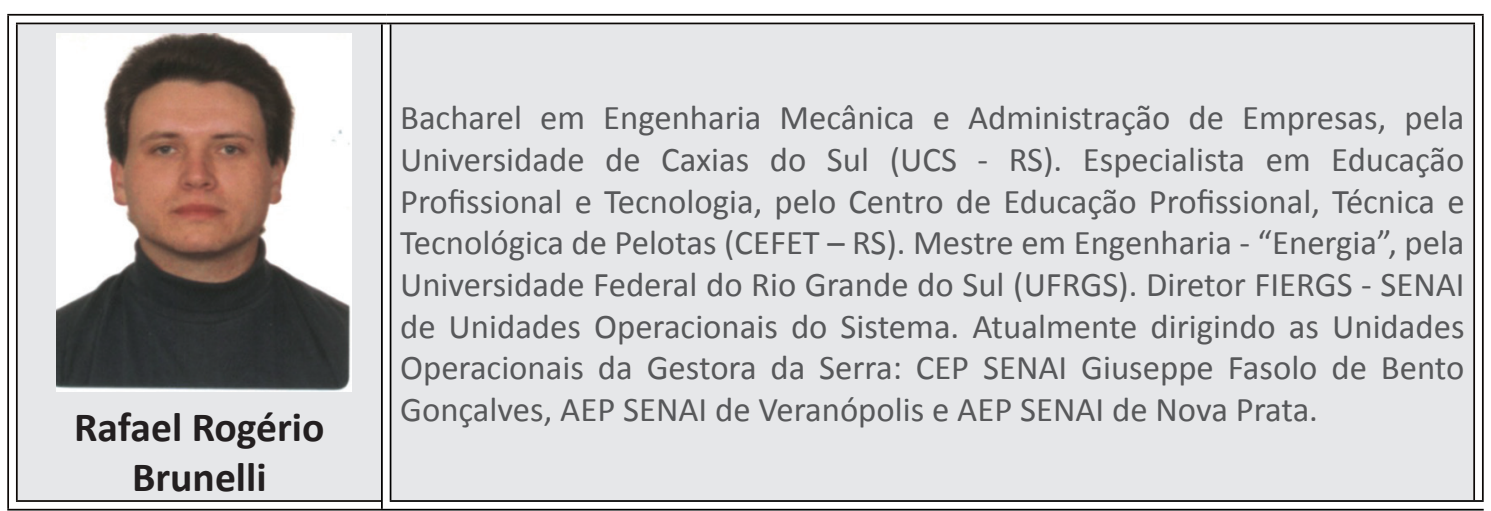

